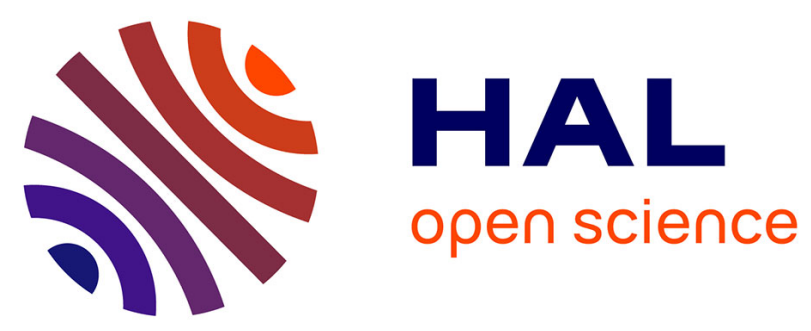

\title{
Competition of Secondary versus Tertiary Carbenium Routes for the Type B Isomerization of Alkenes over Acid Zeolites Quantified by Ab Initio Molecular Dynamics Simulations
}

\author{
Jerôme Rey, Pascal Raybaud, Céline Chizallet, Tomáš Bučko
}

\section{To cite this version:}

Jerôme Rey, Pascal Raybaud, Céline Chizallet, Tomáš Bučko. Competition of Secondary versus Tertiary Carbenium Routes for the Type B Isomerization of Alkenes over Acid Zeolites Quantified by Ab Initio Molecular Dynamics Simulations. ACS Catalysis, 2019, 9 (11), pp.9813-9828. 10.1021/acscatal.9b02856 . hal-02397701

\section{HAL Id: hal-02397701 \\ https://hal-ifp.archives-ouvertes.fr/hal-02397701}

Submitted on 6 Dec 2019

HAL is a multi-disciplinary open access archive for the deposit and dissemination of scientific research documents, whether they are published or not. The documents may come from teaching and research institutions in France or abroad, or from public or private research centers.
L'archive ouverte pluridisciplinaire HAL, est destinée au dépôt et à la diffusion de documents scientifiques de niveau recherche, publiés ou non, émanant des établissements d'enseignement et de recherche français ou étrangers, des laboratoires publics ou privés. 


\section{Competition of Secondary versus Tertiary}

\section{Carbenium Routes for the Type B Isomerization of}

\section{Alkenes over Acid Zeolites Quantified by AIMD}

\section{Simulations}

Jérôme Rey, ${ }^{1}$ Pascal Raybaud, ${ }^{1}$ Céline Chizallet, ${ }^{1, *}$ Tomáš Bučko, ${ }^{2,3, *}$

${ }^{1}$ IFP Energies nouvelles - Rond-Point de l'Echangeur de Solaize - BP 369360 Solaize, France

${ }^{2}$ Department of Physical and Theoretical Chemistry, Faculty of Natural Sciences, Comenius University in Bratislava, Ilkovičova 6, SK- 84215 Bratislava, Slovakia

${ }^{3}$ Institute of Inorganic Chemistry, Slovak Academy of Sciences, Dúbravská cesta 9, SK84236 Bratislava, Slovakia 
ABSTRACT. The skeletal isomerization of alkenes catalyzed by zeolites involves secondary and tertiary carbenium ions which respective reactivity cannot be easily assessed by standard theoretical approaches. Thanks to ab initio molecular dynamics, starting from 4-methyl-hex1-ene (a monobranched $\mathrm{C}_{7}$ alkene), we identify and compare two mechanistic routes for skeletal isomerization: (i) a type B isomerization transforming a secondary carbenium into a tertiary carbenium (conventional route), (ii) a two steps route involving an intramolecular 1,3 hydride-shift producing a tertiary carbenium, followed by a type B isomerization between two tertiary carbenium ions. We find that in the case of the secondary cation, the relevant species from a kinetic point of view is the corresponding $\pi$-complex. The transition states found for type B isomerization reactions are edge-protonated cyclopropanes (edge-PCP) which exhibit similar stabilities and structures. The transition state for the 1,3 hydride shift is an edge-type PCP with one elongated $\mathrm{C}-\mathrm{C}$ bond that is more stable than the one found for type B isomerization. From this analysis, we deduce relevant kinetic constants and quantify the respective contribution of both pathways to the global reaction rate. Although the secondary carbenium ions are poorly stable species, we show that they can hold a significant part of the reaction flux. We finally discuss in details our kinetic and mechanistic insights with previous kinetic modelling data reported in the literature.

KEYWORDS. zeolite, ab initio molecular dynamics, protonated cyclopropane, kinetics, hydroisomerization 


\section{INTRODUCTION}

Zeolite-catalyzed isomerization and cracking reactions of alkenes are core transformations in hydrocarbon chemistry. Many reactions in refining, ${ }^{1,2}$ petrochemistry $^{2,3}$ and biomass conversion $^{4-6}$ involve alkene skeletal isomerization steps. In hydrocracking of alkanes, for example, bifunctional catalysts are required, with a (de)hydrogenation function on a noble metal or a metallic sulfide and an acidic function (of the Brønsted type) provided by zeolites or amorphous silica-aluminas. ${ }^{7}$ Alkenes are protonated on the acid sites of the catalyst before the isomerization and cracking take place. By analogy with conventional organic chemistry, general mechanisms are written with carbenium ions (or classical trivalent carbocations) and carbonium ions (or tetra- or pentacoordinated non-classical carbocations) playing the role of reactive intermediates or of transition states. ${ }^{2,7-10}$ In super-acidic media, it is well-known that secondary carbenium ions are less stable than tertiary carbenium ions. ${ }^{11}$ The only carbenium ions detected experimentally in zeolites are highly resonant tertiary cations. ${ }^{12,13}$ The first direct evidence of the existence of the shorter tert-butyl cation was reported very recently. ${ }^{14,15}$ In pioneering calculations, carbenium ions were considered as transition states whereas alkoxides were identified as stable species. ${ }^{16,17}$ Denayer et al. experimentally observed that the relative intrinsic reaction rates of skeletal branching and cracking reaction steps for various alkanes are catalyst independent (within a series of Pt/USY catalysts), supporting the idea of a carbenium-like reactivity, rather than an alkoxide-mediated one. ${ }^{18}$ With periodic calculations ${ }^{19-22}$ and more sophisticated static calculations, ${ }^{23-25}$ tertiary cations were found to be local energy minima. Using advanced ab initio molecular dynamics methods, van Speybroeck and coworkers concluded that the stability of alkoxides relative to the cationic forms had been overestimated in previous studies. ${ }^{26,27}$ Importantly, the tertiary carbenium ions were found to be stable at $773 \mathrm{~K}$ in the zeolite, whereas secondary cations were shown to be metastable only. Secondary carbenium ions thus appear as transient species. Their stability 
increases with the number of carbons and highly branched carbenium ions undergo fast transformations into more stable cationic species. ${ }^{28}$

The isomerization is classified as type A when it does not involve any branching degree change (in practice, this corresponds to a direct 1,n hydride or alkyl transfer), or type B when it increases the branching degree of the chain. ${ }^{2}$ In the present work, we aim at quantifying the respective reactivity of secondary and tertiary carbenium ions in the skeletal isomerization into a dibranched carbenium ion. It has been demonstrated that finite temperature effects for isomerization and cracking reactions of hydrocarbons in zeolites cannot be described with a sufficient accuracy within the static approach to the transition state theory. ${ }^{26-31}$ Free energy methods based on ab initio molecular dynamics represent the current state-of-art approach to this problem and we adapt this technique (based on the blue moon ensemble approach ${ }^{32,33}$ ) to study the mechanism of isomerization reaction occurring after the protonation of a reactant $\mathrm{C}_{7}$ alkene. $\mathrm{C}_{7}$ alkanes, dehydrogenated into $\mathrm{C}_{7}$ alkenes on the metallic function of bifunctional catalysts, are good model molecules for hydrocraking, representative of the behavior of a large range of molecule sizes, ${ }^{18,34}$ with a large network of isomerization and cracking reactions and a significant effect of confinement on selectivity. ${ }^{35}$

The type B isomerization reaction described in this work increases the branching degree of the reactant (hereafter labelled as $\mathrm{R}$ ), transforming a monobranched secondary carbocation (the 4-methyl-hexen-2-ium cation) into a dibranched tertiary carbocation, the 2,3-dimethylpenten-3-ium cation (latter called $\mathrm{I}_{3}$, Figure 1.a). In this reaction, a single protonated cyclopropane (PCP), non-classical carbocation, is expected as a transition state connecting two classical carbocations. The acid chabazite zeolite is used as a model for the catalyst. In our previous work, ${ }^{31}$ we investigated the mechanism of an isomerization reaction between tertiary carbenium ions, transforming a dibranched into a tri-branched carbenium ion. To the 
best of our knowledge, the isomerization reaction type studied here has never been investigated by any method beyond a simple static approach. ${ }^{36,37,38}$

In this study, we also present an alternative (mechanism II) to the conventional mechanism (mechanism I) of isomerization involving a 1,3 hydride shift between secondary and tertiary carbenium ions (Figure 1.b), that appears to take place spontaneously in the course of certain MD simulations. In experimental and kinetic modeling ${ }^{39}$ practice, it is impossible to conclude about the preferred route. Thus, a detailed investigation of the individual rates is required to determine the intrinsic free energy barriers for the conventional as well as for the alternative reaction mechanisms at relevant temperatures $(300 \mathrm{~K}$ and $500 \mathrm{~K})$ which allows us to compare kinetics of these two pathways.

For that purpose, the crucial question of the correct sampling of the different rotational isomers dictating the mechanisms, which has been overlooked in previous simulations of reactions of hydrocarbons in zeolites, is rigorously addressed here, following the method developed in our previous work. ${ }^{31}$ This question is challenging because a direct sampling of all the conformations is inefficient in a straightforward ab initio molecular dynamics.

The detailed study of these reactions also provides the opportunity to compare the thermal stabilization of secondary carbenium ions in zeolites with respect to that of tertiary carbenium ions. In-depth structural analysis is also performed to identify similarities and differences between type A (methyl shift, 1,3-hydride shift) and type B transition states, considering the results of the present study and our previous work. ${ }^{31}$ Finally, a general ranking between various type A and type B isomerization kinetics at the atomic scale has been obtained, and discussed with the empirically proposed ranking. ${ }^{2,9,11,34,39-42}$ 

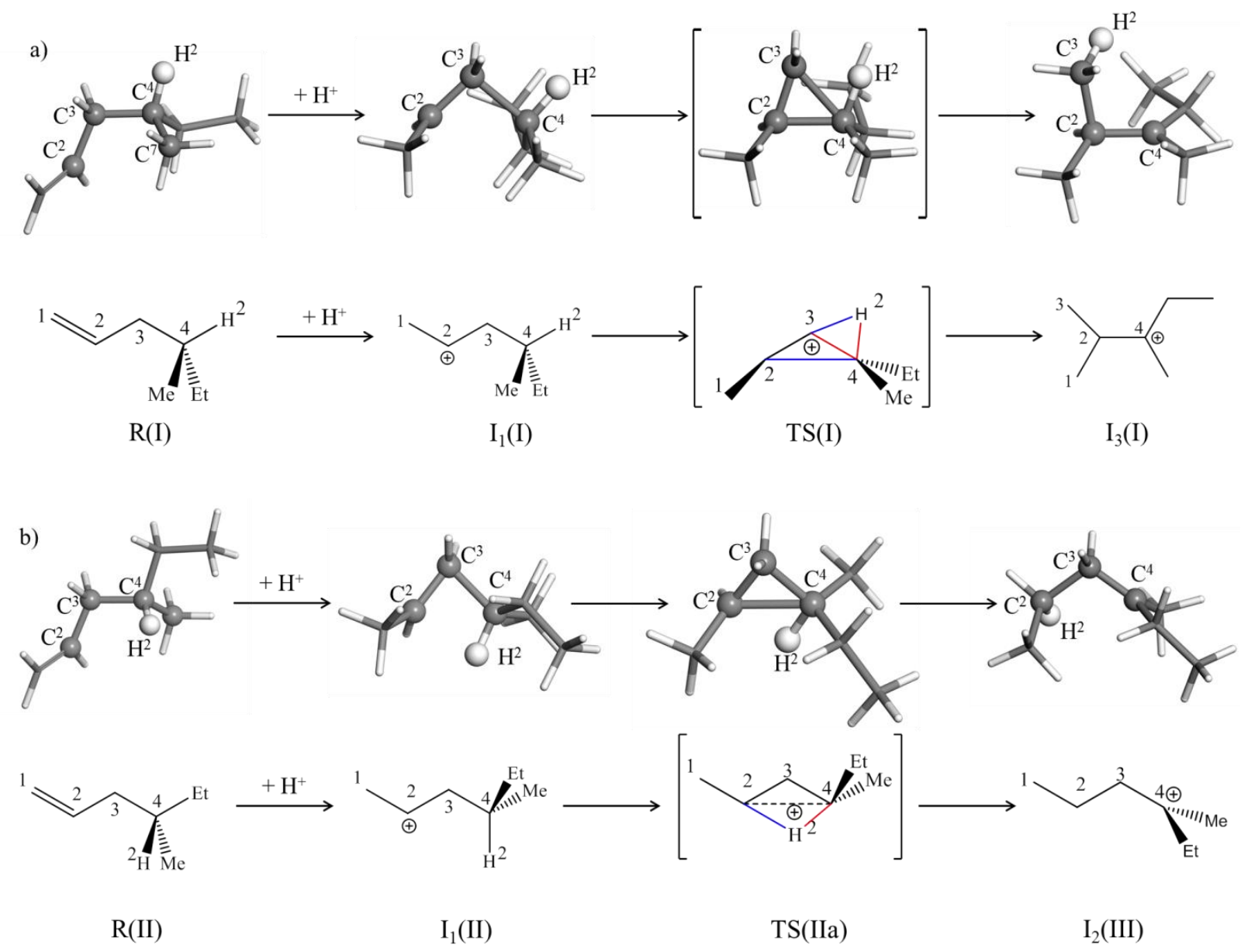

c)

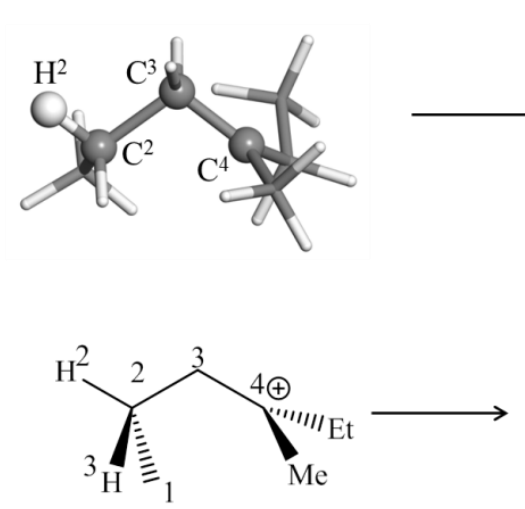

$\mathrm{I}_{2}(\mathrm{II})$
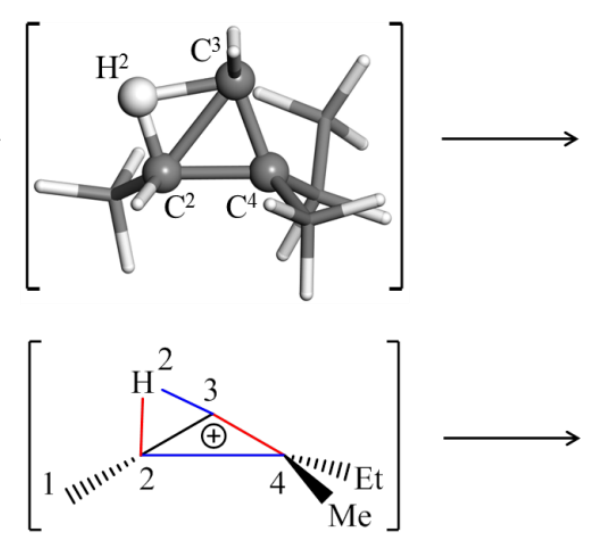

$\mathrm{TS}(\mathrm{IIb})$
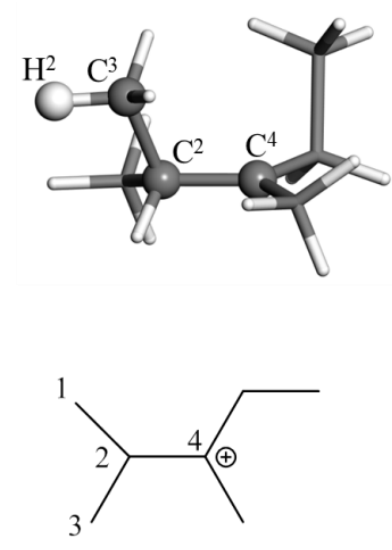

$\mathrm{I}_{3}(\mathrm{III})$

Figure 1. Conventional (mechanisms I) and alternative (mechanism II) mechanisms for the transformation of 4-methyl-hex-1-ene into 2,3-dimethyl-penten-3-ium cation: a) mechanism I - type B isomerization between a secondary and a tertiary carbenium; b) mechanism II, step 1

- 1,3 hydride shift and c) mechanism II, step 2 - type B isomerization between two tertiary 
carbenium ions. The displayed structures have been optimized in zero T relaxations in the gas phase (see Section 2). The blue and red lines indicate the bonds that are, respectively, formed and broken during the reactions. For reactants, intermediates and products, the symbols I, II, and III displayed in brackets refer to different rotational isomers (see Section 3.1 for R and SII of the Supporting Information for $\mathrm{I}_{1}, \mathrm{I}_{2}$ and $\mathrm{I}_{3}$ ).

\section{METHODOLOGY}

Periodic DFT calculations were performed using the VASP code. ${ }^{43-45}$ The Kohn-Sham equations have been solved variationally in a plane-wave basis set using the projector augmented-wave (PAW) method of Blöchl ${ }^{46}$, as adapted by Kresse and Joubert ${ }^{47}$. The PBE exchange-correlation functional in the generalized gradient approximation proposed by Perdew et al. ${ }^{48}$ was used. The D2 correction of Grimme ${ }^{49}$ was applied to account for longrange dispersion interactions taking place upon the adsorption of hydrocarbon molecules in zeolites $^{50-52}$. As a relatively large supercell (see Figure 2 and Section SI of the Supporting Information) was used for describing the chabazite zeolite, the Brillouin zone sampling was restricted to the $\Gamma$-point. A plane-wave cutoff energy of $400 \mathrm{eV}$ was used in all calculations and the convergence criterion for the electronic self-consistency cycle was set to $10^{-6} \mathrm{eV}$.

All relaxations related to the gas phase reactions were performed using the optimization engine GADGET ${ }^{53,54}$ requiring that the forces acting on all atoms be smaller than 0.005 $\mathrm{eV} / \AA \AA$. The intrinsic reaction coordinate ${ }^{55,56}$ (IRC) analysis has been employed using the damped velocity Verlet algorithm ${ }^{57}$ in order to ensure that identified potential energy minima representing reactant and product states are linked by a common path on a potential energy landscape crossing a single first-order saddle point (transition state). The vibrational eigenspectra of resulting potential energy minima and saddle points have been examined in 
order to ensure that the number of imaginary frequencies was correct (i.e zero for reactants and products and one for transition states).

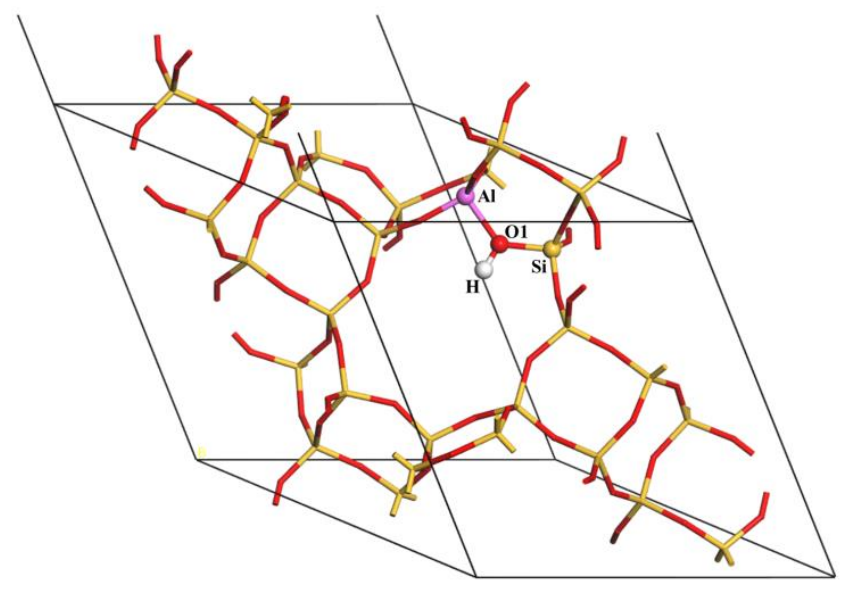

Figure 2. Unit cell of protonated chabazite used in this study.

Born Oppenheimer Molecular dynamics simulations (MD) have been performed in the NVT ensemble. The simulation temperatures of $300 \mathrm{~K}$ and $500 \mathrm{~K}$ have been considered, their average values have been maintained by the Andersen thermostat ${ }^{58}$ with a collision frequency per atom of $0.01 \mathrm{fs}^{-1}$. The classical equations of motion were integrated using the leap-frog algorithm with an integration step of 1 fs. The atomic mass of tritium has been chosen for all $\mathrm{H}$ atoms in order to avoid numerical instabilities possibly caused by the use of a relatively large integration step. Free energies have been computed using the simulation protocol described in Ref. ${ }^{59}$, which is based on the blue moon ensemble method, ${ }^{32,33}$ as implemented in VASP. ${ }^{60}$ In this approach, derived from the transition state theory, ${ }^{58}$ the free-energy of activation $\left(\Delta A^{\ddagger}\right)$ for the process $X \rightarrow Y$ is defined as follows:

$$
\Delta A^{\ddagger}=\Delta A_{\xi_{r e f, X} \rightarrow \xi^{*}}-k_{B} T \ln \left(\frac{h}{k_{B} T} \frac{\left\langle\left|\dot{\xi}^{*}\right|\right\rangle}{2} P\left(\xi_{r e f, X}\right)\right)
$$


where $\Delta A_{\xi_{r e f, X} \rightarrow \xi^{*}}$ is a reversible work needed to shift the value of reaction coordinate $(\xi)$ from some arbitrary reference value characteristic for reactant $\left(\xi_{r e f, X}\right)$ to the value $\xi^{*}$ defining the free-energy transition state, $\left\langle\left|\dot{\xi}^{*}\right|\right\rangle$ is the average velocity of the reaction coordinate at the transition state, and $P\left(\xi_{\text {ref }, X}\right)$ is the probability density of the state $\xi_{\text {ref }, X}$ in ensemble of all reactant (X) configurations. As described in Ref.59, the term $\Delta A_{\xi_{r e f, X} \rightarrow \xi^{*}}$ is obtained from the bluemoon ensemble method, ${ }^{32,33} P\left(\xi_{\text {ref }, X}\right)$ can be determined using the straightforward MD simulations, and $\left\langle\left|\dot{\xi}^{*}\right|\right\rangle$ is computed numerically using a constrained MD with $\xi(r)=\xi^{*}$ (see sections SIII and SIV of the Supporting Information). Free energies of reaction $\left(\Delta A_{X \rightarrow Y}\right)$ are computed similarly:

$$
\Delta A_{X \rightarrow Y}=\Delta A_{\xi_{r e f, X} \rightarrow \xi_{r e f, Y}}-k_{B} T \ln \left(\frac{P\left(\xi_{r e f, X}\right)}{P\left(\xi_{r e f, Y}\right)}\right)
$$

In Equation (2), $\Delta A_{\xi_{r e f, X} \rightarrow \xi_{r e f, Y}}$ is the reversible work needed to shift the value $\xi(\boldsymbol{r})$ from $\xi_{\text {ref }, X}$ to some arbitrary reference value $\xi_{\text {ref,Y }}$ characteristic for product $(\mathrm{P})$, and $P\left(\xi_{\text {ref,Y }}\right)$ is the probability density of the state $\xi_{r e f, Y}$. Equation (2) accounts for the transformation from a generic reactant to a generic product state which are both defined as ensembles of configurations distributed according to the Boltzmann law. ${ }^{61}$ It is an important property of Equations 1 and 2 that the computed free energies are independent of the particular choice of the approximation to the reaction coordinate (provided the approximation drives the transformation from reactant to product reversibly) which is particularly important when comparing the free energetics of chemical reactions differing in reaction mechanisms and consequently also in definitions of $\xi$. The calculation of statistical uncertainties of $\Delta A^{\ddagger}$ and $\Delta A_{X \rightarrow Y}$ is discussed in Section SX of the Supporting Information.

The length of straightforward MD simulations used to determine probability densities of reference states was at least 100 ps (see Section SIV in Supporting Information) while the 9 
length of all constrained MD runs performed within the BM simulations was 50 ps. In each MD run, the initial period of $5 \mathrm{ps}$ has been considered as equilibration and the corresponding data were discarded from the calculations of ensemble averages. Undesired by-reactions, such as the deprotonation of the reactant or product molecules, have been prevented by the use of appropriate restraining potentials described in Section SV of the Supporting Information.

\section{RESULTS}

The scheme describing the conventional mechanism (designated hereafter as the mechanism I) of the 4-methyl-1-hexene isomerization is shown in Figure 1.a. In the first step, the alkene reactant $R(I)$ is protonated to form a secondary carbenium cation $I_{1}(I)$ (4-methylhexen-2-ium cation, the Roman numeral (I) is used to label the specific rotamer involved (vide infra)). Next, the $\mathrm{C}^{2}-\mathrm{C}^{4}$ bond is formed, the $\mathrm{C}^{3}-\mathrm{C}^{4}$ bond is broken, while the hydrogen atom $\mathrm{H}^{2}$ is shifted from $\mathrm{C}^{4}$ to $\mathrm{C}^{3}$. The 2,3-dimethyl-penten-3-ium tertiary cation $\mathrm{I}_{3}$ is obtained. All the events of the latter reaction step are assumed to proceed via a single transition state $(\mathrm{TS}(\mathrm{I}))$ corresponding to a protonated cyclopropane (PCP). ${ }^{2,7,8,35,36}$ Hence, due to steric reasons, this reaction step requires a specific orientation of the shifted hydride with respect to the $C^{3}-C^{4}$ bond in the reaction intermediate $I_{1}(I)$. As a product of this reaction step, tertiary carbenium cation $\mathrm{I}_{3}$ is formed.

In order to learn about the finite-temperature behavior of the system at different stages of reaction, exploratory metadynamics ${ }^{60,62}$ calculations in the NVT ensemble have been performed with $\mathrm{T}=300 \mathrm{~K}$. In these simulations, the cation $\mathrm{I}_{1}(\mathrm{I})$, when created, was almost always transformed into another rotamer (hereafter labeled as $I_{1}(\mathrm{II})$, Figure 1.b) before the expected second reaction step described above started. Hence, instead of observing the $\mathrm{I}_{1}(\mathrm{I}) \rightarrow \mathrm{I}_{3}$ reaction, an alternative process $(1,3$ hydride shift $)$ has been identified leading to 
formation of monobranched tertiary cation (3-methyl-hexen-3-ium cation) $\mathrm{I}_{2}$ (III). Such 1,3 hydride shift reactions have been reported in the literature, as a way to avoid the formation of intermediate secondary carbenium ions, and as an alternative to two consecutive 1,2 hydride shifts. ${ }^{40}$ As the state $\mathrm{I}_{2}(\mathrm{II})$ can be transformed into the $\mathrm{I}_{3}$ formed in the conventional reaction mechanism, we consider the $\mathrm{I}_{1}(\mathrm{II}) \rightarrow \mathrm{I}_{2} \rightarrow \mathrm{I}_{3}$ sequence as an alternative reaction route (mechanism II).

\subsection{Characterization of the reactant state}

a) Gas phase simulations

As discussed in the previous section, the different variants of isomerization mechanism of 4-methyl-1-hexene require different internal geometry of the reactant molecule. The relevant geometry changes can be controlled via variation of the dihedral angle $(\tau)$ between atoms $C^{2}$ $C^{3}-C^{4}-C^{7}$ (Figure 3) in a gas phase simulation. It is therefore instructive to explore the dependence of potential energy of the reactant molecule in the gas phase on this parameter. The corresponding potential energy profile ( $\Delta \mathrm{V}$ vs. dihedral angle $\tau$ ) obtained in a series of constrained relaxations with a fixed value of $\tau$ is shown in Figure 4. Three stable rotamers (corresponding to potential energy minima) have been identified (Figure 3). The corresponding structures, hereafter labelled as R(I), R(II), and R(III), are nearly degenerate in energy, the difference between the lowest (R(III)) and the highest (R(I)) energy states being only $\sim 3 \mathrm{~kJ} / \mathrm{mol}$. The rotamers $\mathrm{R}(\mathrm{II})$ and $\mathrm{R}(\mathrm{III})$ are separated by a relatively low barrier of $\sim 13$ $\mathrm{kJ} / \mathrm{mol}$, while the two barriers separating the state $\mathrm{R}(\mathrm{I})$ from the other two rotamers are $\sim 5$ $\mathrm{kJ} / \mathrm{mol}$ higher. When the molecule is protonated to create cation $\mathrm{I}_{1}$, the corresponding potential energy profile changes significantly (Figure 4) whereby only two stable rotational isomers, $\mathrm{I}_{1}(\mathrm{I})$ and $\mathrm{I}_{1}(\mathrm{II})$, are identified (Figure $\mathrm{S} 1$ in Supporting information). The protonation of the rotamer $\mathrm{R}(\mathrm{I})$ leads to formation of a secondary cation $\mathrm{I}_{1}(\mathrm{I})$ in which the value of $\tau$ remains basically unchanged. Interestingly, the protonation of $\mathrm{R}(\mathrm{II})$ and $\mathrm{R}(\mathrm{III})$ at fixed $\tau$ 
would create unstable structures that both relax to the same minimum $I_{1}($ II) when the constraint is removed. The cation $\mathrm{I}_{1}(\mathrm{II})$ is significantly $(15 \mathrm{~kJ} / \mathrm{mol})$ lower in energy compared to the $I_{1}(I)$ state. The barrier for the $I_{1}(\mathrm{II}) \rightarrow \mathrm{I}_{1}(\mathrm{I})$ transformation $(31 \mathrm{~kJ} / \mathrm{mol})$ increases dramatically compared to the barriers determined for the neutral molecule, while that for the reverse process remains modest $(15 \mathrm{~kJ} / \mathrm{mol})$. All these results explain the behavior observed in our exploratory metadynamics run (vide supra), as $\mathrm{I}_{1}(\mathrm{II})$ is the rotamer giving rise to the 1,3 hydride shift instead of the direct isomerization (via TS(I)). In particular, it is obvious that, due its significantly lower energy, the $\mathrm{I}_{1}$ (II) state is formed with a greater likelihood than the rotamer $\mathrm{I}_{1}(\mathrm{I})$. Moreover, even if the state $\mathrm{I}_{1}(\mathrm{I})$ is formed, it is likely to transform into $\mathrm{I}_{1}(\mathrm{II})$ before the reaction $I_{1}(I) \rightarrow I_{3}$ is completed, which follows from the fact that the barrier for the transformation is at least a factor four lower compared to that for the reaction (vide infra).
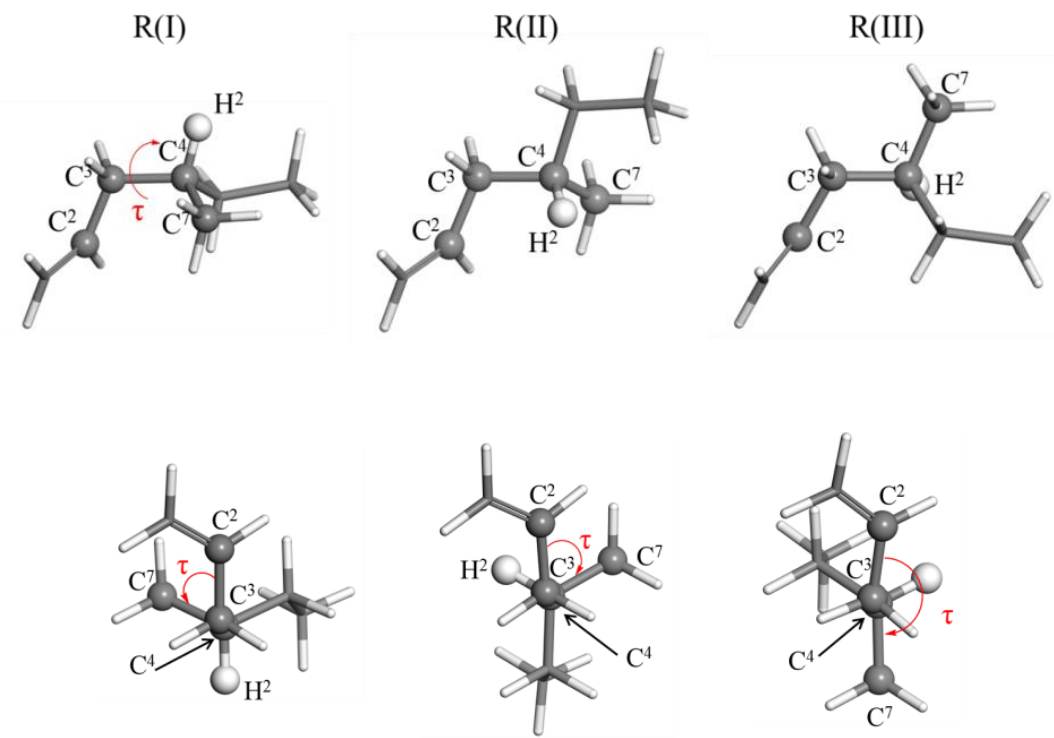

Figure 3. Rotational isomers $\mathrm{R}(\mathrm{I})\left(\tau \approx-60^{\circ}\right), \mathrm{R}(\mathrm{II})\left(\tau \approx 60^{\circ}\right)$ and $\mathrm{R}(\mathrm{III})\left(\tau \approx 180^{\circ}\right)$ of the reactant 4-methyl-hexene, obtained for the gas phase reaction. Top panels: side view; bottom panels: front view chosen so that the atom $\mathrm{C}^{4}$ overlaps the atom $\mathrm{C}^{3}$. 


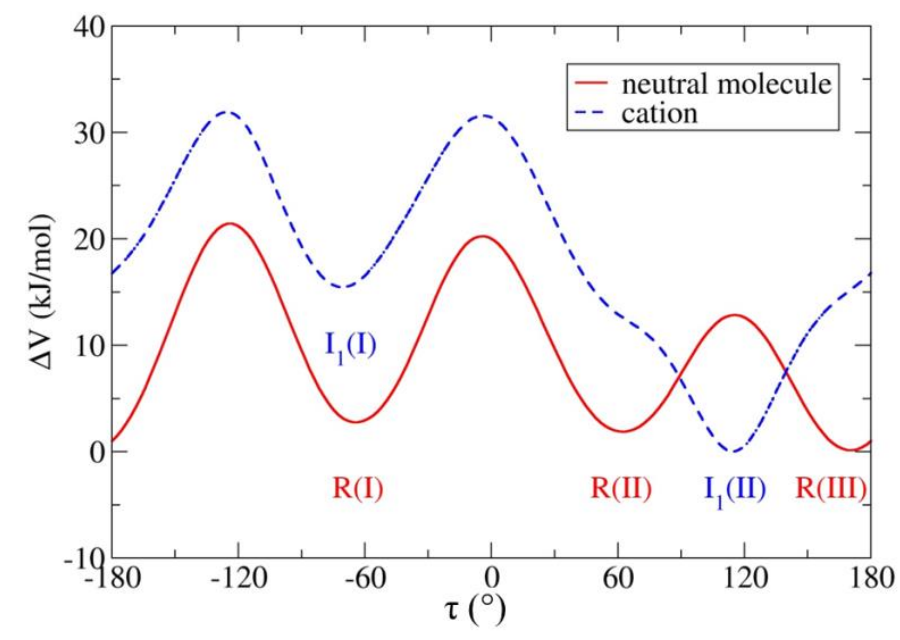

Figure 4. Potential energy as a function of dihedral angle $(\tau)$ defined by the atoms $C^{2}, C^{3}, C^{4}$, and $\mathrm{C}^{7}$ (cf. Figure 3) computed using constrained relaxations of neutral molecule (R) and cation (I1) in the gas phase. Zero on the energy axis is defined by the lowest energy found for each profile.

b) Reactant adsorbed in chabazite

Next, we shall examine whether the results from our analysis of the molecular systems remain valid for the reaction taking place in zeolite at finite temperature. To this end, a blue moon simulation has been carried out for the reactant molecule in $\mathrm{CHA}$ to study the free energy as a function of $\tau$ for $\mathrm{T}=300 \mathrm{~K}$ and $500 \mathrm{~K}$. This constrained blue moon simulation has been performed using a grid of 20 integration points evenly distributed over the interval $-180^{\circ} \leq \tau<180^{\circ}$. The computed free energy profiles are presented in Section SII.2 of the Supporting Information. The shapes of the free energy profiles at both temperatures are qualitatively similar to the potential energy determined for the neutral molecule (Figure 4) indicating that the energetics of the internal rotation of molecule is determined mainly by mutual interactions of atoms constituting it, while the confining environment provided by 
zeolite can be considered as a small perturbation to the relative stability of rotamers. The observed modest thermal effect is not unexpected for a monomolecular reaction. We note that a free energy profile cannot be determined for the secondary cation $\mathrm{I}_{1}$ in chabazite, because of its too short lifetime given by the fact that this state is not a deep free energy minimum and it easily transforms into $\pi$-complexes or alkoxides (see Sections 3.2 and 3.3).

For the purpose of further analysis (see later, Sections 3.2 and 3.3), we determine the likelihoods of occurrence of individual rotamers among all reactant states. Using the free energy profile $A(\tau)$, the likelihood of the state $\mathrm{R}(\mathrm{I})$ is computed as follows:

$$
p(R(I))=\frac{\int_{\tau_{\max , 1}}^{\tau_{\max , 2}} \exp \left(-\frac{A(\tau)}{k_{B} T}\right) d \tau}{\int_{-180^{\circ}}^{180^{\circ}} \exp \left(-\frac{A(\tau)}{k_{B} T}\right) d \tau}
$$

where $\tau_{\max , 1}$ and $\tau_{\max , 2}$ are the positions of the first and the second maxima on the free energy profile shown in Figure S2 of the Supporting Information, respectively. Probabilities for states $\mathrm{R}(\mathrm{II})$ and $\mathrm{R}(\mathrm{III})$ are defined analogically. The values of $p(R(I)), p(R(I I))$, and $p(R(I I I))$ computed for $\mathrm{T}=300 \mathrm{~K}$ are $5.8 \%, 55.7 \%$ and $38.5 \%$, respectively. At $\mathrm{T}=500 \mathrm{~K}$, these values change to $16.7 \%, 49.8 \%$ and $33.5 \%$ respectively.

\subsection{Mechanism I}

All terms needed to determine the free energies of activation and of reaction via Equations (1) and (2) are summarized in Table 1. The free energy profiles $(\Delta A(\xi))$, corresponding to the reversible work needed to shift the value of reaction coordinate from the reference value characteristic for reactant to the given value of $\xi$, have been computed using the blue moon ensemble approach. ${ }^{32,33}$ The following approximation to the reaction coordinate has been chosen: 


$$
\xi=\frac{d\left(C^{1}-H^{1}\right)}{d\left(O^{1}-H^{1}\right)}+\frac{d\left(C^{3}-H^{2}\right)}{d\left(C^{4}-H^{2}\right)}
$$

where $d(X-Y)$ stands for distance between atoms $X$ and $Y$ and the labelling of atoms is as explained in Figure 5. This approximation to reaction coordinate involves only the moving hydrogen atoms and the atoms (oxygen and/or carbon) to which they are bound at various stages of the reaction. The skeletal rearrangement of carbon atoms turns out to be a consequence of the proton transfer driven by $\xi$.

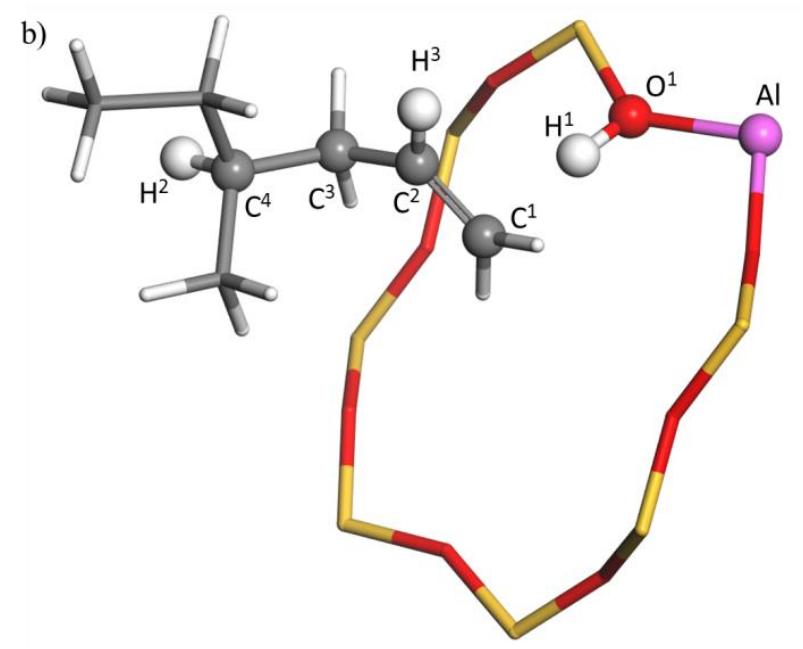

Figure 5. $\pi$-complex of 4-methyl-hex-1-ene adsorbed in chabazite with numbering of the atoms used in Equation (4).

For the integration of free energy gradients, a mesh of 22 points has been used covering the intermediate states distributed between the alkene molecule $(R(I))$ and the tertiary carbenium ion $I_{3}$. The reference state $\left(\xi_{r e f, R}=3.76\right)$ has been chosen as a high likelihood state identified on probability distribution function determined for $\mathrm{R}(\mathrm{I})$ using straightforward $\mathrm{MD}$ (Section SIV.1 of the Supporting Information). The resulting free energy profiles are shown in Figure 6. The transition state $\operatorname{TS}(\mathrm{I})\left(\xi^{*}=1.56\right.$ for both temperatures $)$ has been identified as the maximum on $\Delta A(\xi)$. The variation of selected geometric parameters along the reaction 
coordinate has been monitored to illustrate the transformation from $\mathrm{R}(\mathrm{I})$ to $\mathrm{I}_{3}$ (Figure $\mathrm{S} 18$ in Section SXI of the Supporting Information).

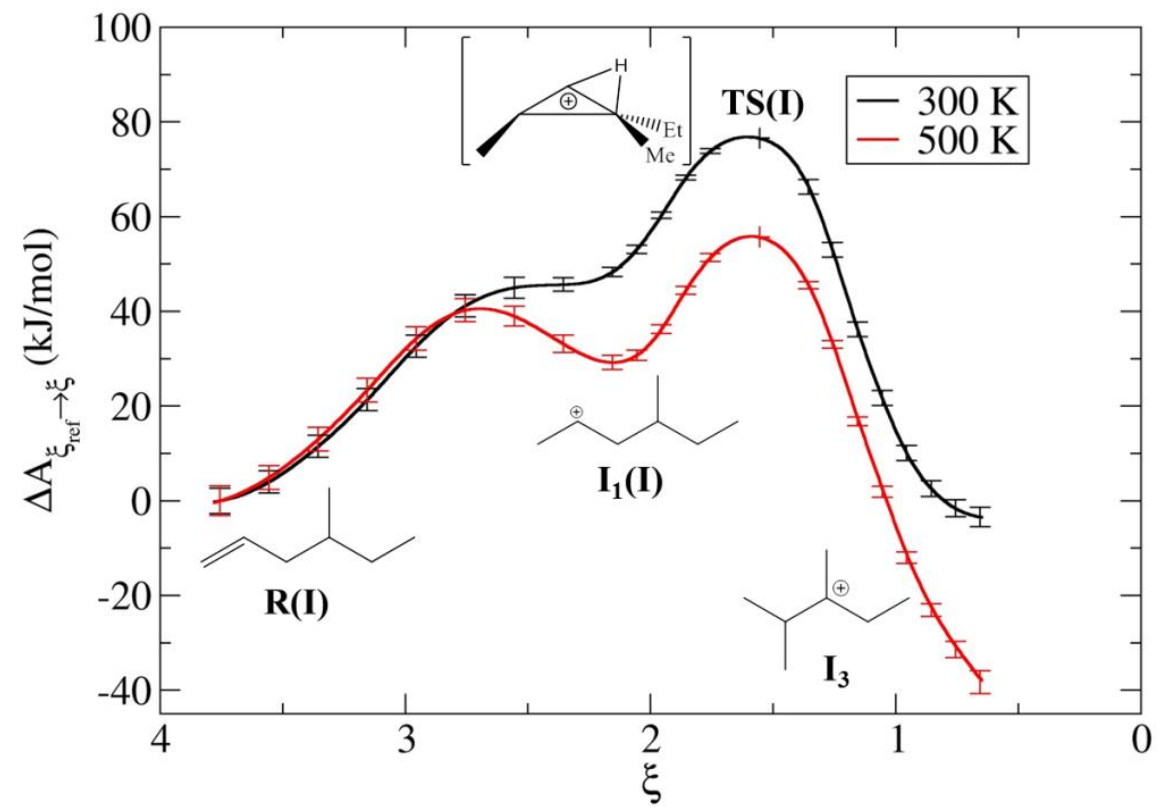

Figure 6. Free energy profiles, $\Delta A_{\xi_{r e f} \rightarrow \xi}$, computed using the blue moon ensemble approach for the isomerization reaction via mechanism (I) in chabazite at $\mathrm{T}=300 \mathrm{~K}$ and $500 \mathrm{~K}$. The error bars are determined from the standard errors of the free energy gradients. ${ }^{60}$

The initial parts of profiles, ranging between the reference value for the alkene $(\xi=3.76)$ and the transition state of protonation $\left(\xi^{*}=2.76\right)$ and corresponding to the protonation of the alkene, are very similar for both temperatures. The transition state of protonation becomes apparent at $500 \mathrm{~K}$ as a consequence of the stabilization of the secondary cation (vide infra) and its structure can be characterized by measuring the two distances changing during the protonation, $\mathrm{O}^{1}-\mathrm{H}^{1}(1.47 \AA)$ and $\mathrm{C}^{1}-\mathrm{H}^{1}(1.26 \AA)$ (Figure $\mathrm{S} 16$ in Section SVIII.3 of the Supporting Information). 
The second part of the profile, ranging from $\xi=2.76$ to $\xi=2.16$ (the secondary carbenium ion), exhibits significant variations with $\mathrm{T}$, which can be explained by the relative entropic stabilization of free forms (carbenium ions) with respect to the bound forms ( $\pi$-complexes). A similar conclusion was reported by Cnudde and coworkers when comparing the $\pi$-complexes, alkoxides and carbenium ions formed by pentene in H-ZSM-5. ${ }^{26-28}$ The stabilization of the cationic form has a significant impact on the value of the term $\Delta A_{\xi \text { ref,R } \rightarrow \xi^{*}}$ constituting a major contribution to the free energy of activation (see Equation (1)): its value decreases from $76.6 \pm 5.4 \mathrm{~kJ} / \mathrm{mol}$ to $55.7 \pm 6.4 \mathrm{~kJ} / \mathrm{mol}$ as $\mathrm{T}$ is raised from $300 \mathrm{~K}$ to $500 \mathrm{~K}$. We note that the secondary cation has a classical structure (Figure 1 and Section SVIII.2 of the Supporting Information) in agreement with the fact that non-classical hydrido-bridged structures $^{63,64}$ are only found at very low temperatures. ${ }^{65}$

The third part of the profile corresponds to the monomolecular transformation between the secondary $(\xi=2.16)$ and tertiary $(\xi=0.66)$ cations by the type B isomerization. TS(I) is an edge-protonated cyclopropane (Figure 1), the structure of which will further be discussed in Section 4.2. As expected for a monomolecular transformation, the thermal effect is weak and, as evident from the almost identical shapes of profiles computed for different $\mathrm{T}$ (the segments with $1<\xi<2.16$ can be brought into an almost perfect coincidence via a simple rigid shift by $18 \mathrm{~kJ} / \mathrm{mol}$ ), a large part of this profile is virtually independent of temperature. This result is also in line with our static gas phase simulations predicting only a small increases in free energy of activation for the forward (by $5.9 \mathrm{~kJ} / \mathrm{mol}$ ) and reverse (by 5.2 $\mathrm{kJ} / \mathrm{mol}$ ) modes of the $I_{1} \rightarrow I_{3}$ transformation when $\mathrm{T}$ is increased from $300 \mathrm{~K}$ to $500 \mathrm{~K}$. As evident from the data presented in Table S8, these small variations in free energy of activation originate mainly in vibrational entropy which decreases (due to looser bonding) when transition state is formed in either direction of transformation. The difference between 
the final and the initial state $\left(\Delta A_{\xi_{\text {ref,R }} \rightarrow \xi_{\text {ref, I }}}\right)$ contributing to the free energy of reaction (Equation 2) increases significantly with $\mathrm{T}(-3.4 \pm 6.8 \mathrm{~kJ} / \mathrm{mol}(300 \mathrm{~K})$ and $-37.5 \pm 8.0 \mathrm{~kJ} / \mathrm{mol}$ $(500 \mathrm{~K}))$, which is given by the relative stabilization of the cationic form with respect to the $\pi-$ complex. Once again, the origin of the major part of the difference in $\Delta A_{\xi_{r e f, R} \rightarrow \xi_{r e f, I_{3}}}$ computed for different $\mathrm{T}$ can be traced back to the region between $\xi=2.76$ and 2.16 where the protonation of reactant is completed and the newly formed secondary cation is fully detached from the zeolite framework, gaining thus in entropy due to newly acquired hindered translations.

Following the idea developed in our previous study, ${ }^{31}$ the term $P\left(\xi_{\text {ref }, R}\right)$ is defined as follows:

$$
P\left(\xi_{r e f, R}\right)=\tilde{P}\left(\xi_{r e f, R}\right) p(R(I))
$$

where $\tilde{P}\left(\xi_{r e f, R}\right)$ is the probability density of the configuration $\xi_{r e f, R}$ among the configurations of rotational isomer R(I) $(0.94(300 \mathrm{~K})$ and $0.34(500 \mathrm{~K})$, see Section SIV.1 of the Supporting Information), and $p(R(I))$ is the probability to find rotamer $\mathrm{R}(\mathrm{I})$ among all reactant configurations. The formulation via Equation (5) allows us to compute $P\left(\xi_{\text {ref,R }}\right)$ efficiently despite the relatively high free energy barriers separating the individual rotamers. In particular, the term $\tilde{P}\left(\xi_{\text {ref,R }}\right)$ is determined using a straightforward MD run performed for the rotational isomer $\mathrm{R}(\mathrm{I})$ and the probability $p(R(I))$ is obtained from the free energy profiles $A(\tau)$ as discussed in Section 3.1.

Finally, the term $P\left(\xi_{\text {ref, } I_{3}}\right)$ needed in the calculations of $\Delta A_{R \rightarrow I_{3}}$ has been determined for $\xi_{r e f, I_{3}}=0.66$. Because of the presence of four different rotational isomers separated by small but significant barriers (Section SII.4 of the Supporting Information), the determination of $\tilde{P}\left(\xi_{\text {ref }, I_{3}}\right)$ has been performed with dedicated blue moon simulations (Section SIV.3 of the 
Supporting Information). The resulting free energy differences take into account generic states (i.e states in which all rotational isomers are distributed according to the Boltzmann law) of the reactant $\mathrm{R}$ and of all the considered intermediates $-\mathrm{I}_{3}$ and $\mathrm{I}_{2}$, see later section 3.3..

The computed free energies of activation are $84.1 \pm 5.4 \mathrm{~kJ} / \mathrm{mol}(300 \mathrm{~K})$ and $69.2 \pm 6.4$ $\mathrm{kJ} / \mathrm{mol}(500 \mathrm{~K})$. As evident, the decrease of $\Delta A^{\ddagger}$ with $\mathrm{T}$ is slightly less significant than that for $\Delta A_{\xi_{r e f, R} \rightarrow \xi^{*}}$ obtained from the free energy profiles.

The free energies of reaction computed for $300 \mathrm{~K}$ and $500 \mathrm{~K}$ are $6.0 \pm 6.8 \mathrm{~kJ} / \mathrm{mol}$ and -25.3 $\pm 8.0 \mathrm{~kJ} / \mathrm{mol}$, respectively. This trend, once again, reflects the stabilization of the cationic form with respect to the $\pi$-complex. Although the difference in $\Delta A_{R \rightarrow I_{3}}$ is very similar to that computed for $\Delta A_{\xi_{\text {ref }, R} \rightarrow \xi_{\text {ref,I }}}$, the numerical values computed for the fixed $\mathrm{T}$ differ significantly (see Table 1) which is primarily caused by the additional positive work needed to create the initial reactant configuration and which is accounted for only in the former term. This result, together with the significant differences in the $\Delta A^{\ddagger}$ values underline the importance of correct treatment of all terms in the free energy calculations.

Table 1. The values of computed terms used in the calculation of free energies of activation ( $\left.\Delta A^{\ddagger}\right)$ and of reaction $\left(\Delta A_{X \rightarrow Y}\right)$ via Equation (1) and (2), respectively.

\begin{tabular}{|c|c|c|c|c|c|c|c|}
\hline \multicolumn{8}{|c|}{ Mechanism I } \\
\hline $\begin{array}{c}\mathrm{T} \\
(\mathrm{K})\end{array}$ & $\left\langle\left|\dot{\xi}^{*}\right|\right\rangle\left(\mathrm{s}^{-1}\right)$ & $\mathrm{P}\left(\xi_{\text {ref,R }}\right)$ & $P\left(\xi_{\text {ref }, I_{3}}\right)$ & $\begin{array}{c}\Delta A_{\xi_{r e f, R} \rightarrow \xi^{*}} \\
(\mathrm{~kJ} / \mathrm{mol})\end{array}$ & $\begin{array}{c}\Delta A^{\ddagger} \\
(\mathrm{kJ} / \mathrm{mol})\end{array}$ & $\begin{array}{c}\Delta A_{\xi_{\text {ref, } R} \rightarrow \xi_{\text {ref, } I_{3}}} \\
(\mathrm{~kJ} / \mathrm{mol})\end{array}$ & $\begin{array}{c}\Delta A_{R \rightarrow I_{3}} \\
(\mathrm{~kJ} / \mathrm{mol})\end{array}$ \\
\hline 300 & $1.10 \cdot 10^{13}$ & 0.055 & 2.39 & $76.6 \pm 5.4$ & $84.1 \pm 5.4$ & $-3.4 \pm 6.8$ & $6.0 \pm 6.8$ \\
\hline 500 & $1.40 \cdot 10^{13}$ & 0.057 & 1.08 & $55.7 \pm 6.4$ & $69.2 \pm 6.4$ & $-37.5 \pm 8.0$ & $-25.3 \pm 8.0$ \\
\hline \multicolumn{8}{|c|}{ Mechanism II, step 1} \\
\hline $\begin{array}{c}\mathrm{T} \\
(\mathrm{K})\end{array}$ & $\left\langle\left|\dot{\xi}^{*}\right|\right\rangle\left(\mathrm{s}^{-1}\right)$ & $\mathrm{P}\left(\xi_{\text {ref,R }}\right)$ & $P\left(\xi_{r e f, I_{2}}\right)$ & $\begin{array}{c}\Delta A_{\xi_{r e f, R} \rightarrow \xi^{*}} \\
(\mathrm{~kJ} / \mathrm{mol})\end{array}$ & $\begin{array}{c}\Delta A^{\ddagger} \\
(\mathrm{kJ} / \mathrm{mol})\end{array}$ & $\begin{array}{c}\Delta A_{\xi_{r e f, R} \rightarrow \xi_{r e f, I_{2}}} \\
(\mathrm{~kJ} / \mathrm{mol})\end{array}$ & $\begin{array}{c}\Delta A_{R \rightarrow I_{2}} \\
(\mathrm{~kJ} / \mathrm{mol})\end{array}$ \\
\hline 300 & $1.08 \cdot 10^{13}$ & 0.84 & 2.38 & $58.7 \pm 4.6$ & $59.5 \pm 4.6$ & $-0.1 \pm 7.8$ & $2.6 \pm 7.8$ \\
\hline 500 & $1.45 \cdot 10^{13}$ & 0.37 & 4.87 & $51.5 \pm 5.6$ & $57.1 \pm 5.6$ & $-21.0 \pm 7.5$ & $-10.3 \pm 7.5$ \\
\hline \multicolumn{8}{|c|}{ Mechanism II, step 2} \\
\hline $\begin{array}{c}\mathrm{T} \\
(\mathrm{K})\end{array}$ & \langle|$\dot{\xi}^{*}$ & $P\left(\xi_{r e f, I_{2}}\right)$ & $\left.f, I_{3}\right)$ & $\begin{array}{c}\Delta A_{\xi_{\text {ref }, I_{2}} \rightarrow \xi^{*}} \\
(\mathrm{~kJ} / \mathrm{mol})\end{array}$ & $\begin{array}{c}\Delta A^{\ddagger} \\
(\mathrm{kJ} / \mathrm{mol})\end{array}$ & $\begin{array}{c}\Delta A_{\xi_{\text {ref, } I_{2}} \rightarrow \xi_{\text {ref, } I_{3}}} \\
(\mathrm{~kJ} / \mathrm{mol})\end{array}$ & $\begin{array}{l}\Delta A_{I_{2} \rightarrow I_{3}} \\
(\mathrm{~kJ} / \mathrm{mol})\end{array}$ \\
\hline 300 & $9.90 \cdot 10^{12}$ & 1.54 & 0.44 & $77.8 \pm 2.6$ & $77.3 \pm 2.6$ & $0.3 \pm 3.0$ & $-2.8 \pm 3.0$ \\
\hline 500 & $1.26 \cdot 10^{13}$ & 0.93 & 1.46 & $83.8 \pm 4.1$ & $86.2 \pm 4.1$ & $2.4 \pm 4.8$ & $4.2 \pm 4.8$ \\
\hline
\end{tabular}




\subsection{Mechanism II}

Mechanism II consists of two elementary reaction steps, namely the transformation from the $\pi$-complex $\mathrm{R}$ to the intermediate tertiary cation $\mathrm{I}_{2}$, and the type $\mathrm{B}$ isomerization reaction from $I_{2}$ to $I_{3}$ (Figure 1). These two activated processes are explored in two independent sets of simulations with the following approximations to the reaction coordinates (see Figure 5 for the numbering): the transformation between the $\pi$-complex and the tertiary cation $I_{2}$ is described by the following parameter

$$
\xi_{a}=\frac{d\left(C^{1}-H^{1}\right)}{d\left(O^{1}-H^{1}\right)}+\frac{d\left(C^{2}-H^{2}\right)}{d\left(C^{4}-H^{2}\right)}
$$

while the transformation between two tertiary cations $I_{2}$ and $I_{3}$ is studied using the parameter

$$
\xi_{b}=\frac{d\left(C^{3}-H^{2}\right)}{d\left(C^{2}-H^{2}\right)}
$$

The blue moon simulations have been performed using 20 integration points distributed along $\xi_{a}$ and 22 integration points along $\xi_{b}$ and the resulting free energy profiles are displayed in Figure 7. The variation of selected geometric parameters along the reaction coordinate has been monitored to illustrate the transformation from R(II) to $I_{2}$ and from $I_{2}$ to $I_{3}$ (Figure $S 19$ and S20 in Section SXI of the Supporting Information). 

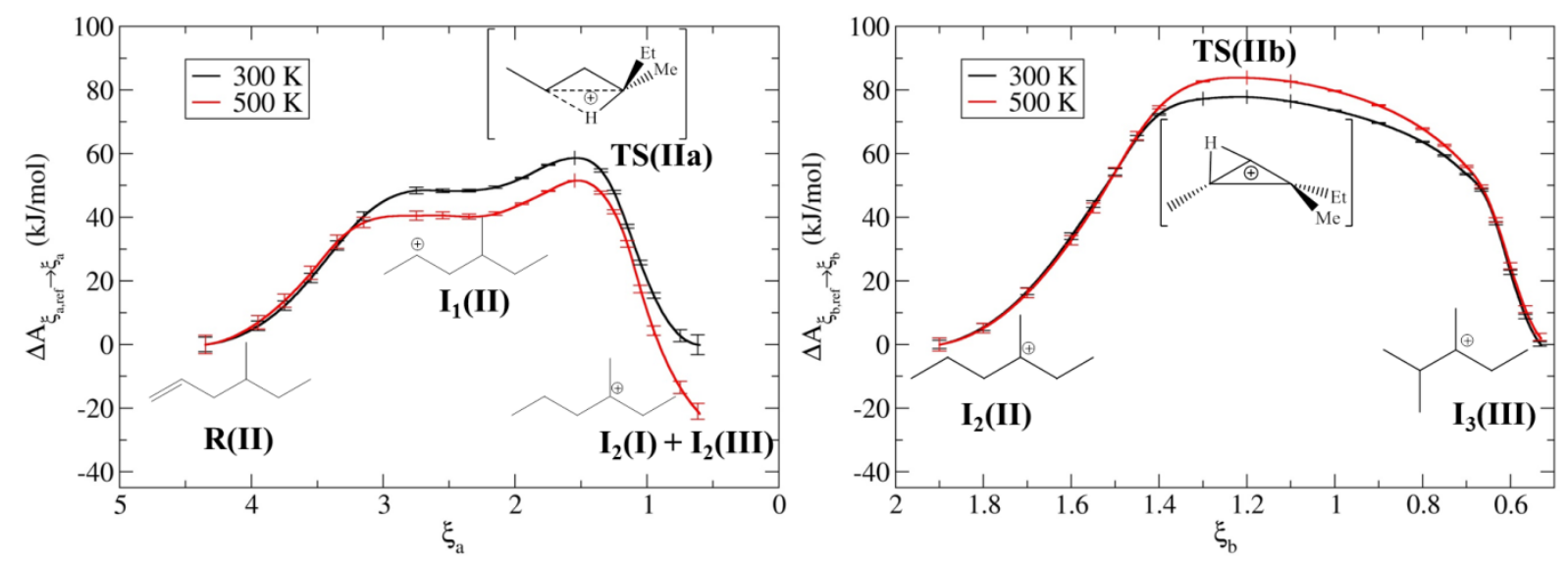

Figure 7. Free energy profiles, $\Delta A_{\xi_{\text {ref }} \rightarrow \xi}$, for the transformations between the $\pi$-complex R and the intermediate tertiary cation $I_{2}$ (left), and between the tertiary cations $I_{2}$ and $I_{3}$ (right) taking place within the mechanism (II) of isomerization of 4-methyl-hex-1-ene into 2,3dimethyl pent-2-ene.

The free energy profile for the first step starting from the $\pi$-complex of rotamer $\mathrm{R}$ (II) $\left(\xi_{\text {ref }, R}=4.35\right)$ exhibits some of the features observed in the case of the mechanism I. First, the part of the profile corresponding to the protonation of $\mathrm{R}(\xi<3.30)$ is nearly identical at both temperatures. Second, the difference between profiles computed for different temperatures develops in a narrow region $(3.30 \leq \xi<2.80)$ where a metastable secondary cation is formed. As before, this difference is related to the thermal stabilization of the cationic forms with respect to the $\pi$-complex. Third, the region where the monomolecular 1,3 hydride shift between secondary and tertiary cation occurs $(2.80 \leq \xi)$ is nearly temperature independent (i.e. the two profiles can be brought into coincidence via a shift by a constant). This latter finding is consistent with the gas phase results reported in Table S9 predicting a very modest increase in the free activation barrier for the $I_{1} \rightarrow I_{2}$ transformation due to 
increased temperature $(2.1 \mathrm{~kJ} / \mathrm{mol}(300 \mathrm{~K})$ and $5.4 \mathrm{~kJ} / \mathrm{mol}(500 \mathrm{~K}))$. The computed values of $\Delta A_{\xi_{r e f, R} \rightarrow \xi^{*}}$ and $\Delta A_{\xi_{r e f, R} \rightarrow \xi_{r e f, I_{2}}}$ for $\mathrm{T}=300 \mathrm{~K}$ are $58.7 \pm 4.6 \mathrm{~kJ} / \mathrm{mol}$ and $-0.1 \pm 7.8 \mathrm{~kJ} / \mathrm{mol}$, respectively. As a consequence of the thermal stabilization of the cation, $\Delta A_{\xi_{\text {ref,R }} \rightarrow \xi^{*}}$ and $\Delta A_{\xi_{\text {ref,R },} \rightarrow \xi_{\text {ref,I }}}$ decrease to $51.5 \pm 5.6 \mathrm{~kJ} / \mathrm{mol}$ and $-21.0 \pm 7.5 \mathrm{~kJ} / \mathrm{mol}$, respectively, when $\mathrm{T}$ is increased to $500 \mathrm{~K}$. The free energy transition state for the 1,3 hydride shift occurs at $\xi^{*} \approx 1.56$ and its structure is similar to that of the reaction in the gas phase (see Figure 1 ), i.e. it can be considered as an edge-protonated cyclopropane (see Section 4.2). The values of $P\left(\xi_{\text {ref,R }}\right)$ were computed as described in Sec. 3.2. As two different rotamer states $\left(\mathrm{I}_{2}(\mathrm{I})+\right.$ $\mathrm{I}_{2}(\mathrm{III})$ ) separated by relatively large free energy barriers are present, dedicated blue moon sampling simulations have been performed (Section SII.3 of the Supporting Information) to determine $P\left(\xi_{\text {ref, } I_{2}}\right)$ in order to obtain free energy differences between generic states of the reactant $R$ and of the intermediate $\mathrm{I}_{2}$.

Regarding the overall shape of the profile, its flatness close to the secondary carbenium ion is a consequence of processes occurring during this reaction step. The initial steep region corresponds to a proton transfer - here the proton is shifted from zeolite to alkene, one bond is broken and one bond is formed causing thus the large increase in free energy. This process also requires that a part of hydrocarbon chain be relatively close to the $\mathrm{O}$ atoms next to $\mathrm{Al}$ because proton cannot be transferred over a very long distance. Next, carbenium cation is shifted farther away from the Al site and, due to the thermal motion it now also assumes various random orientations within the zeolite. At the same time, the molecule starts to deform so as to allow for easier H-shift (in the next step). No bond is broken nor created in this diffusion-like process and hence only a very modest change in free energy is observed. Finally, the cation rearranges into another form (secondary to tertiary), multiple bonds are formed and broken resulting, again, in a relatively large changes in free energy. 
All terms needed to compute free energies of activation and of reaction via Equations (1) and (2) are compiled in Table 1.

Unlike the term $A_{\xi_{r e f, R} \rightarrow \xi^{*}}$, the free energy of activation $\Delta A^{\ddagger}$ is nearly independent of temperature, with the numerical values being $59.5 \pm 4.6 \mathrm{~kJ} / \mathrm{mol}(300 \mathrm{~K})$ and $57.1 \pm 5.6$ $\mathrm{kJ} / \mathrm{mol}(500 \mathrm{~K})$.

The values $\Delta A_{R \rightarrow I_{2}}$ computed for the first step of mechanism II are $2.6 \pm 7.8 \mathrm{~kJ} / \mathrm{mol}(300 \mathrm{~K})$ and $-10.3 \pm 7.5(500 \mathrm{~K})$ and these values are, again, much lower than $A_{\xi_{\text {ref, } R} \rightarrow \xi_{\text {ref, } I_{2}}}$. Up to this point, the first step of mechanism II has been discussed as proceeding via the rotamer R(II). Note, however, that the states R(II) and R(III) are similar in structure (they differ only by the exchange of methyl and ethyl group on $\mathrm{C}^{4}$ atom, see Figure 3) and they are nearly energy degenerate (Figures 4 and S2 in the Supporting Information). Furthermore, as discussed in Section 3.1, they form the same intermediate secondary cation $\mathrm{I}_{2}$ upon their protonation. The reaction involving $\mathrm{R}(\mathrm{III})$ should differ from the one proceeding via $\mathrm{R}(\mathrm{II})$ only in the initial part. Hence it is reasonable to consider R(III) as another microstate of reactant that is active in mechanism II, and this fact can be taken into account by modifying the term $P\left(\xi_{r e f, R}\right)=\tilde{P}\left(\xi_{r e f, R}\right)(p(R(I I))+p(R(I I I)))$ used in Equation (1) making use of the fact that the probability distribution functions $\tilde{P}\left(\xi_{\text {ref }, R}\right)$ for $\mathrm{R}(\mathrm{II})$ and $\mathrm{R}(\mathrm{III})$ are very similar. Such a modification leads to a very small decrease of the free energy of activation $\Delta A^{\ddagger}$, which is now $58.0 \pm 4.6(300 \mathrm{~K})$ and $54.6 \pm 5.6 \mathrm{~kJ} / \mathrm{mol}(500 \mathrm{~K})$ and of the free energy of reaction $\Delta A_{R \rightarrow I_{2}}$ that changes to $1.1 \pm 7.8(300 \mathrm{~K})$ and $-12.8 \pm 7.5 \mathrm{~kJ} / \mathrm{mol}(500 \mathrm{~K})$.

In the second reaction step, one form of tertiary cation $\mathrm{I}_{2}$ (II) (3-methyl-hexen-3-ium cation) is transformed into another one $\mathrm{I}_{3}(\mathrm{III})$ (2,3-dimethyl-penten-3-ium cation) via a type $\mathrm{B}$ isomerization reaction. The transition state is again an edge-protonated cyclopropane (see Section 4.2). As shown in Figure 7, the free energy profiles computed for two different 23 
temperatures differ mainly in the transition region $(0.7 \leq \xi<1.5)$, while the regions close to the states $I_{2}(\xi \approx 1.90)$ and $I_{3}(\xi \approx 0.53)$ are nearly temperature independent. In particular, restricted molecular vibrations in the transition state $\left(\xi^{*} \approx 1.56\right)$ are responsible for negative activation entropy $^{31}$ (see Table S10 for the relevant static gas phase data) causing an increase in $\Delta A_{\xi_{r e f, I 2} \rightarrow \xi^{*}}$ with T $(77.8 \pm 2.6 \mathrm{~kJ} / \mathrm{mol}(300 \mathrm{~K})$ vs. $83.8 \pm 4.1 \mathrm{~kJ} / \mathrm{mol}(500 \mathrm{~K}))$. Taking into account the contributions from $P\left(\xi_{\text {ref, } I_{2}}\right)=\tilde{P}\left(\xi_{\text {ref, } I_{2}}\right) \cdot p\left(I_{2}(I I)\right)$ and $\left\langle\left|\dot{\xi}^{*}\right|\right\rangle$ (see Table 1) determined as described in Section SIV of the Supporting Information, the free energy of activation $\Delta A_{I_{2} \rightarrow T S}^{\ddagger}$ computed for $300 \mathrm{~K}$ and $500 \mathrm{~K}$ is $77.3 \pm 2.6 \mathrm{~kJ} / \mathrm{mol}$ and $86.2 \pm 4.1$ $\mathrm{kJ} / \mathrm{mol}$, respectively. These results are in excellent agreement with the values of $74.4 \pm 3.4$ $\mathrm{kJ} / \mathrm{mol}(300 \mathrm{~K})$ and $83.4 \pm 3.6 \mathrm{~kJ} / \mathrm{mol}(500 \mathrm{~K})$ reported in our previous work for a similar reaction involving related but different reactant (2,4-dimethyl-penten-2-ium cation). ${ }^{31}$

Due to the similarity between the initial and the final state of this reaction, the term $\Delta A_{\xi_{\text {ref, } I_{2}} \rightarrow \xi_{\text {ref }, I_{3}}}$ is very small $(0.3 \pm 3.0 \mathrm{~kJ} / \mathrm{mol}(300 \mathrm{~K})$ and $2.4 \pm 4.8 \mathrm{~kJ} / \mathrm{mol}(500 \mathrm{~K}))$. Also the values of $P\left(\xi_{r e f, I_{2}}\right)$ and $P\left(\xi_{r e f, I_{3}}\right)$ differ only modestly within the given temperature (see Table 1) and hence the computed free energies of reaction $\Delta A_{I_{2} \rightarrow I_{3}}$ are only $-2.8 \pm 3.0 \mathrm{~kJ} / \mathrm{mol}$ and $4.2 \pm 4.8 \mathrm{~kJ} / \mathrm{mol}$. The latter results compare very well with the values of $1.9 \pm 3.8 \mathrm{~kJ} / \mathrm{mol}$ and $3.7 \pm 4.2 \mathrm{~kJ} / \mathrm{mol}$, obtained for the type B isomerization of 2,4-dimethyl-penten-2-ium cation reported in our previous work. ${ }^{31}$

\section{DISCUSSION}

\subsection{Thermal variation of the overall free energy profiles}

The overall free energy profiles computed according to Equations (1) and (2) for both mechanisms at $300 \mathrm{~K}$ and $500 \mathrm{~K}$ are compared in Figure 8. 

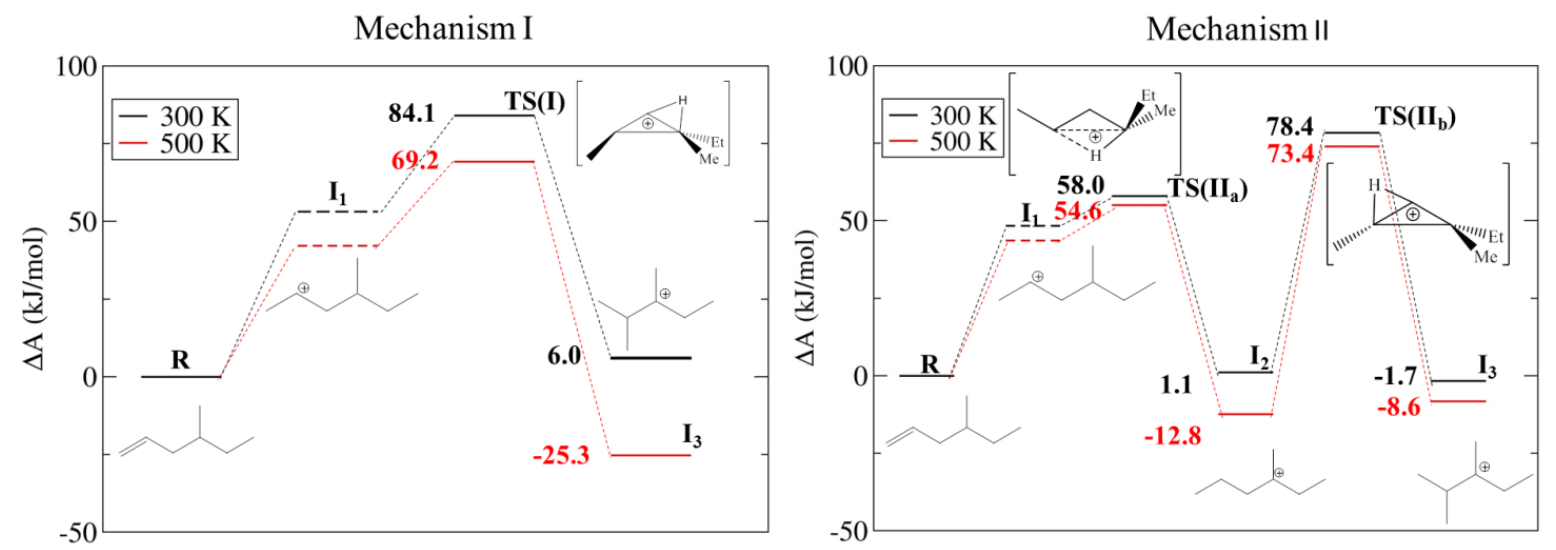

Figure 8. Overall free energy profiles for mechanisms I and II at $300 \mathrm{~K}$ and $500 \mathrm{~K}$. A qualitative estimate of the free energy of secondary cation $I_{1}$ is indicated by a dash line.

The dominant trend governing the thermal variation of the free energy profiles is the thermal stabilization of all free cationic species with respect to the neutral $\pi$-complex considered as reactant, by $6-33 \mathrm{~kJ} / \mathrm{mol}$. This is mainly entropic effect that favors unbonded forms over the structures in which the molecular motion is restricted due to interactions with zeolite and it has been reported also in the previous theoretical work by Cnudde et al. comparing the relative stabilities of $\pi$-complexes, alkoxides and carbenium ions formed by pentene in H-ZSM-5. ${ }^{10,11,13}$ Another factor contributing to the shape of the overall free energy profile is the shift of transition states towards higher free energies with respect to the carbenium intermediate which is caused by vibrational entropy changes during the transformation. As we discussed in our previous work, ${ }^{31}$ this effect can be estimated reasonably well by using a simple gas phase model and we utilized the same approach also in this work. As typical for monomolecular reactions, all transition states found for mechanisms I and II are more constrained than the corresponding stable states linked via common reaction coordinate leading to negative vibrational entropy of activation. As shown in Tables S8-S10, this entropy term always dominates over the internal energy contribution of relevant gas 25 
phase reactions and consequently the free energy of activation increases when $\mathrm{T}$ is raised from $300 \mathrm{~K}$ to $500 \mathrm{~K}$ (by $5.9 \mathrm{~kJ} / \mathrm{mol}, 3.3 \mathrm{~kJ} / \mathrm{mol}$, and $5.5 \mathrm{~kJ} / \mathrm{mol}$ for mechanism $\mathrm{I}$, and first and second steps of mechanism II, respectively).

The relative free energies of the state $\mathrm{I}_{3}$ created in both mechanisms should be identical. However, the statistical error, mainly due to the accumulation of uncertainties in free energy gradients integrated over the all reaction paths, and the systematic error, e.g. due to the noise in forces computed at the DFT level, numerical integration errors, or the use of approximations to reaction coordinate, cause the values of $\Delta A_{R \rightarrow I_{3}}$ computed for both mechanisms to differ. For the lower temperature, this difference $(7.7 \mathrm{~kJ} / \mathrm{mol})$ is well below the theoretical limit $1.96 \sqrt{\sigma_{I}^{2}+\sigma_{I I, 1}^{2}+\sigma_{I I, 2}^{2}}=10.8 \mathrm{~kJ} / \mathrm{mol}$, with $\sigma_{I}$ and $\sigma_{I I, 1}$ and $\sigma_{I I, 2}$ being the standard errors determined for the free energies of reaction for mechanisms I, and steps 1 and 2 of the mechanism II (Table 1), respectively, and the factor 1.96 corresponds to $95 \%$ confidence interval assumed throughout this work. Hence the difference in $\Delta A_{R \rightarrow I_{3}}$ computed for the two reaction routes at $300 \mathrm{~K}$ is not statistically significant. For the higher $\mathrm{T}$, the values of $\Delta A_{R \rightarrow I_{3}}$ differ by $16.7 \mathrm{~kJ} / \mathrm{mol}$, which is slightly more than the theoretical value computed from the individual statistical uncertainties $\left(1.96 \sqrt{\sigma_{I}^{2}+\sigma_{I I, 1}^{2}+\sigma_{I I, 2}^{2}}=12.0 \mathrm{~kJ} / \mathrm{mol}\right)$ indicating that our high temperature results are, to a modest extent, affected by the errors, statistical or systematic, which are hard to control. Performing longer simulations could reduce the statistical uncertainty of the computed free energies but it would be extremely expensive: it follows from the definition of standard error that its reduction by a factor of 2 would require a factor 4 longer MD trajectories. 
In any case, it is clear from our results that the relative free energy of the final state $\mathrm{I}_{3}$ decreases when $\mathrm{T}$ is increased, and it is also evident that the temperature tends to stabilize the state $\mathrm{I}_{3}$ relative to $\mathrm{R}$.

\subsection{Comparison of structure and stability of the transition states for the 1,3 hydride}

\section{shift and type $B$ isomerization}

Although the TS(I), TS(IIa) and TS(IIb) transition states show some structural similarities (they apparently all belong to the edge-protonated PCP family), they are very different in terms of stability (15-26 kJ/mol between TS(I) and TS(IIa), 19-20 kJ/mol between TS(IIa) and TS(IIb)). Indeed, the uncertainty in free energy differences between first transition states of both mechanisms is much smaller with respect to the uncertainty in free energy differences between $\mathrm{I}_{3}$ from mechanisms I and II $\left(17 \mathrm{~kJ} / \mathrm{mol}\right.$ on $\mathrm{I}_{3}$ at $\left.500 \mathrm{~K}\right)$. This is because the path taken from the initial state $\mathrm{R}$ is shorter and the number of terms contributing to the error is smaller.

A deeper structural analysis may help in the identification of relevant differences between these states. First, we showed that different rotamers of the reactant are involved in the 1,3 hydride shift or type B isomerization reaction, which explains the difference between seemingly similar transition states. This conclusion confirms the intuition of Brouwer and Hogeven who suggested, in an early work, that the existence of a high rotational energy barrier between conformations of the reactant could be responsible for the difference between the rates of these two reactions. ${ }^{11}$ Concerning the 1,3 hydride shift, which is considered as a type $\mathrm{A}$ isomerization because it induces no change in the branching degree, ${ }^{2}$ we find that the transition state is an edge-protonated PCP (TS(IIa)). However, its free energy is significantly lower as compared to the transition states of the type B isomerization reactions (TS(I) and TS(IIb)). According to our static gas phase simulations, the free energy difference between transition states with seemingly similar structures considered here stems mainly from the 27 
electronic energy $A_{e l}$. In fact, $A_{e l}$ for the TS(IIa) formed in the gas phase is $26.3 \mathrm{~kJ} / \mathrm{mol}$ lower than that of TS(I) and $35.1 \mathrm{~kJ} / \mathrm{mol}$ lower than that computed for TS(IIb) (Table S7 in Section SVII of the Supporting Information). Our calculations are in qualitative agreement with known experimental facts. In measurements performed in superacid solutions at $-80^{\circ} \mathrm{C}$, for instance, it was demonstrated that the 1,3 hydride shift between tertiary cations (starting from 2,4-dimethyl-penten-3-ium) is much easier than type B isomerization reactions. The experimentally deduced Gibbs free energy barriers are $36 \mathrm{~kJ} / \mathrm{mol}$ and $71 \mathrm{~kJ} / \mathrm{mol}$ for the 1,3 hydride shift and type B isomerization, respectively. ${ }^{11,40}$ A qualitatively similar conclusion was obtained with DFT (B3LYP) calculations on $\mathrm{C}_{6}$ species in the gas phase (with potential energy barriers of $72 \mathrm{~kJ} / \mathrm{mol}$ for the $1,3 \mathrm{H}$-shift (tertiary to secondary cation) and $94 \mathrm{~kJ} / \mathrm{mol}$ for the type B isomerization starting from the same tertiary cation). ${ }^{38}$

The analysis of the distributions of the bonds involved in the transition states (Figure 9 and Table S11 in Section SVIII.1 of the Supporting Information) can provide some insight into the structural differences between the three protonated cyclopropanes (TS(I), TS(IIA) and TS(IIb)). In our blue moon simulations, the $\mathrm{C}-\mathrm{C}$ distance between the two $\mathrm{C}$ atoms holding the extra hydrogen atom in TS(IIa) $\left(\mathrm{C}^{2}-\mathrm{C}^{4}\right)$ is longer than in $\mathrm{TS}(\mathrm{I})\left(\mathrm{C}^{3}-\mathrm{C}^{4}\right)$ and $\mathrm{TS}(\mathrm{IIb})\left(\mathrm{C}^{2}-\mathrm{C}^{3}\right)$. The strength of this $\mathrm{C}-\mathrm{C}$ bond is also much weaker, mainly at $500 \mathrm{~K}$ (see Section SVIII.1 of the Supporting Information). This difference may be at the origin of the electronic energy difference between the 1,3 hydride shift transition state and other PCPs for type B isomerization reactions. As compared to other PCPs, the $\mathrm{C}^{2}-\mathrm{C}^{4}$ bond in TS(IIa) is elongated to $1.89 \AA$ (for $\mathrm{T}=300 \mathrm{~K}$ ) and $1.92 \AA$ (for $\mathrm{T}=500 \mathrm{~K}$ ) but since the average distance does not exceed $2 \AA$ it is still possible to classify TS(IIa) as a PCP. The structure of the transition state for the 1,3 hydride shift reactions has been the subject of an intense debate in the literature ${ }^{11,40,66-68,64}$ devoted to super-acidic media, discussing its PCP nature versus a four 
center TS. The PCP-type structure of TS(IIa) obtained in our MD simulations is consistent with structures proposed at the MP2 level. ${ }^{64}$

The type B isomerization reactions transition states (TS(IIb) and TS(I)) only differ in the location of the edge proton, see Figure 1. Their free energies (Figure 8) and local structures described by length of C-C bonds constituting PCP are similar (Figure 9 and Table S11 in Section SVIII.1 of the Supporting Information). As compared to TS(IIa), the lengths of bonds $\mathrm{C}^{3}-\mathrm{C}^{4}$ in TS(I) and $\mathrm{C}^{2}-\mathrm{C}^{3}$ in TS(IIb) where the $\mathrm{H}^{2}$ atom is located, are smaller $(1.808 \AA$ and $1.757 \AA$ for $\mathrm{T}=300 \mathrm{~K})$. Moreover, all interatomic distances within the $\mathrm{C}^{2}-\mathrm{C}^{3}-\mathrm{C}^{4}$ cycle in TS(I) and $\mathrm{TS}(\mathrm{IIb})$ are rather insensitive to change in temperature, whereas the corresponding interatomic distances in TS(IIa) vary significantly with $\mathrm{T}$. This result reflects the constrained nature of the TS(I) and TS(IIb) PCP, whereas TS(IIa) is intrinsically more flexible. The transition state $\mathrm{TS}(\mathrm{IIb})$, between monobranched to dibranched tertiary carbenium ions (mechanism II), is also comparable to that for the related transformation between dibranched to tribranched tertiary carbenium ions investigated in our previous paper. ${ }^{31}$ These results suggest a certain degree of universality among the kinetic parameters of similar chemical reactions, even if the branching degree of the carbenium ion is different. The stability of the PCP for such reactions is not strongly affected by the number of alkyl groups attached to the cyclopropane ring, in agreement with previous findings made in super-acidic media. ${ }^{11}$

Of course the question remains of the impact of the level of theory on the calculated stability of the various charged compounds investigated. Going beyond DFT may be needed to reach chemical accuracy when describing carbenium ions. ${ }^{24,25,69,70}$ It was recently shown that the barriers of some reactions involving carbenium ions (methylation and cracking, unfortunately isomerization reactions were not investigated) are underestimated by PBE-D3 with respect to MP2. ${ }^{71,72}$ On the contrary, with respect to hydride shifts reactions, Vrček et al. ${ }^{64}$ show that DFT predicts higher barriers than MP2. However, combining this level of 29 
calculation with the MD approach in a rigorous way is currently prohibitive, opening perspectives for the future. ${ }^{73}$

a)

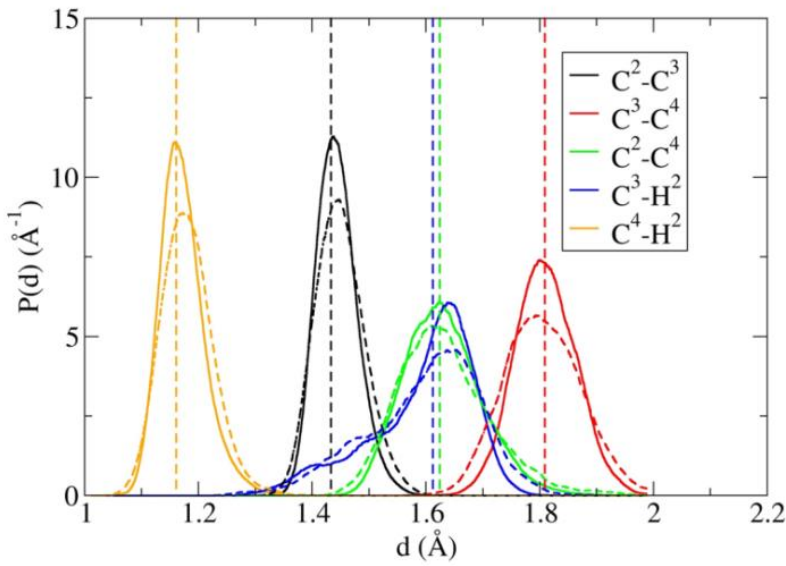

b)

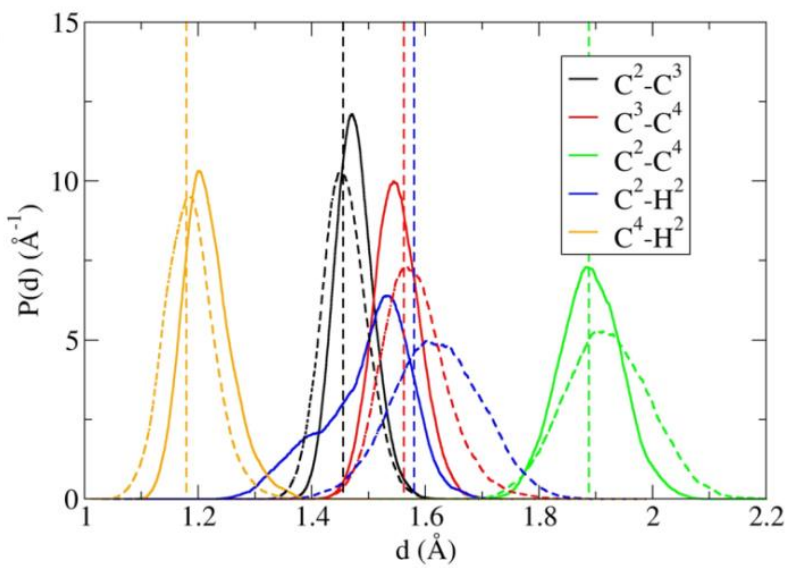

c)

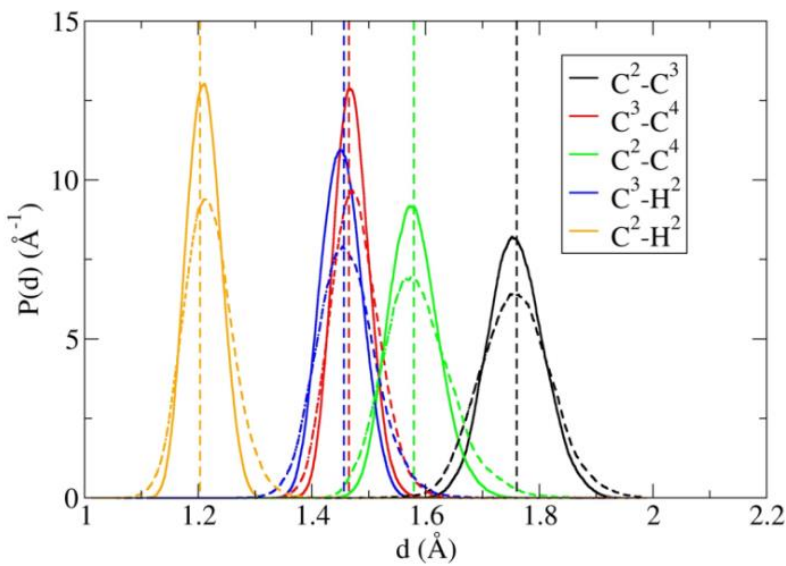

TS(I)

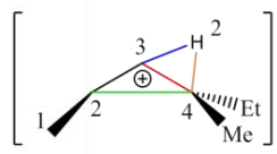

TS(IIa)

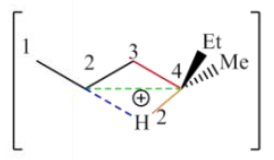

TS(IIb)

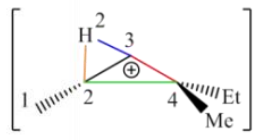

Figure 9. Probability distribution functions of selected $\mathrm{C}-\mathrm{C}$ and $\mathrm{C}-\mathrm{H}$ bonds in the transition states of (a) mechanism (I), (b) mechanism II, step 1, and (c) mechanism II, step 2 determined using MD at $300 \mathrm{~K}$ (solid lines) and $500 \mathrm{~K}$ (dash lines). The static approach results in gas phase are reported by vertical dashed lines. 


\subsection{Implication for the kinetic modeling of isomerization reaction networks}

\subsubsection{Relative contributions of mechanisms I and II}

As shown in Figure 8, the free energies of the least stable transition states are rather similar for both mechanism. It is therefore not obvious from these energy profiles which reaction mechanism is favorable as a function of temperature. We plugged the rate constants, determined via the Eyring equation ${ }^{74}$ from the free energies reported in this work into a kinetic model treating the reactions $\mathrm{R} \rightleftharpoons \mathrm{I}_{3}$ and $\mathrm{R} \rightleftharpoons \mathrm{I}_{2} \rightleftharpoons \mathrm{I}_{3}$ as parallel competing processes (see Section SVI of the Supporting Information). We terminated our simulations when $10 \%$ of reactant was converted into the final state $I_{3}$, rendering the reverse reactions from the final state that are most significantly affected by the statistical errors of free energies of activation (see Section 4.1.) unimportant. We find that the mechanism II is predominant at $\mathrm{T}=300 \mathrm{~K}$ : a higher fraction of the product $\left(\mathrm{I}_{3}\right)$ molecules is formed via this reaction route $(79.0 \pm 1.6 \%)$ as compared to mechanism I $(21.0 \pm 1.6 \%)$. When the temperature is raised to $500 \mathrm{~K}$, the least stable transition state of mechanism II lies $73.4 \mathrm{~kJ} / \mathrm{mol}$ above the reactant on the free energy scale. Remarkably, this value is close to that determined for $300 \mathrm{~K}(78.4 \mathrm{~kJ} / \mathrm{mol})$, suggesting that the effective barrier for this mechanism is only weakly temperature dependent. In contrast, the barrier for mechanism I decreases to $69.2 \mathrm{k} / \mathrm{mol}$. This significant change causes that the mechanism I becomes predominant at $500 \mathrm{~K}$ (according to our kinetic model, $75.4 \pm 1.4 \%$ of product molecules are formed via this mechanism). Even considering the statistical uncertainty in the results of our kinetic model which is given by the uncertainty in the computed free energies (see Table 1), our results clearly show that both reaction mechanisms occur with significant frequencies (although with varying relative contributions) for the temperatures considered in this work. 
4.3.2. Comparison with kinetic modeling reported in the literature

Reaction networks for alkene isomerization (embedded in hydroisomerizationhydrocracking models) have been the object of numerous kinetic modeling approaches, ${ }^{75}$ from simple global kinetics ${ }^{3,18,76}$ up to single-event models. ${ }^{9,34,39,41,42,77-79}$ In the latter case, the whole network of elementary steps is defined, and species are gathered in lumps, defined by the carbon number and the degree of substitution of the carbenium (mono, di and tribranched). Each rate constant for the transformation of a lump into another one is written as a combination of parameters which depend on the type of reactant and product carbenium (secondary: s, tertiary: $\mathrm{t}$, primary carbenium are discarded). A set of assumptions is generally made, and mechanistic conclusions are drawn from the fitting of experimental data, that we can now discuss in the light of our ab initio molecular dynamics results.

In kinetic modeling, the entropy of the physisorbed state (that we consider to be the $\pi$ complex) is often considered to be higher than that of the carbenium ions, ${ }^{34,39}$ considering that the adsorbed olefin still has the same rotational entropy as in the gas phase, while at least a part of translational entropy is expected to be lost upon adsorption. According to our simulations, this last assumption is confirmed as the physisorbed state is confined to the neighborhood of the Brønsted acid site of the zeolite. Indeed, in free MD runs corresponding to the $\pi$-complex (see Section SIX of the Supporting Information), the distance between the center of the $\mathrm{C}=\mathrm{C}$ bond and the proton on the zeolite exhibits a sharp maximum close to 2.1 $\AA$, meaning that a big part of the translational entropy of the molecule in the gas phase is lost upon adsorption.

In microkinetic models, however, the enthalpy of the $\pi$-complex is supposed to be higher than that of the carbenium by about 110 (secondary) to 150 (tertiary) $\mathrm{kJ} / \mathrm{mol} .{ }^{39}$ More recent 32 
estimations predicted protonation enthalpies of the secondary and tertiary olefins of -65 $\mathrm{kJ} / \mathrm{mol}$ and $-95 \mathrm{~kJ} / \mathrm{mol}$, respectively. ${ }^{9}$ Even if in our static simulations in gas phase we cannot easily connect the enthalpic behavior of the $\pi$-complex with respect to that of carbenium ions, such a difference should lead to a better stability of carbenium ions with respect to $\pi$ complexes. ${ }^{34}$ Our MD results (in terms of free energies, Figure 8) do not confirm this scheme (that they established in terms of enthalpy). In particular, the $I_{1}$ secondary carbenium ion is about $40 \mathrm{~kJ} / \mathrm{mol}$ less stable than the corresponding $\pi$-complex. For tertiary carbenium ion, the free energy levels are more or less comparable to that of the $\pi$-complex. In practice however, the kinetic modeling is not performed by fitting the protonation versus intrinsic isomerization activation free energies, but their sum (see below), so that the quality of the fitting is not affected by this erroneous representation of the relative energy levels. Also, in their estimate of the relative protonation enthalpy yielding secondary versus tertiary carbenium ions, Martens et al. ${ }^{39}$ and Thybaut et al. ${ }^{9}$ find that the enthalpy of tertiary carbenium ions is 40 $\mathrm{kJ} / \mathrm{mol}$ lower than that of secondary carbenium. Our current estimations are in very good agreement with these results.

Within the lumping approach, the (monobranched, dibranched or tribranched) species are connected by type A isomerization reactions (hydride or alkyl transfers), observed to be much quicker than type B isomerization reactions. ${ }^{39}$ As discussed in the previous section, this is in qualitative agreement with our findings involving the 1,3-hydride shift studied here and the methyl shift reported in our previous work. ${ }^{31}$ Note, however, that the free energy of the 1,3hydride shift transition state (TS(IIa)) is not significantly lower than that of the type B isomerization transition states (about $20 \mathrm{~kJ} / \mathrm{mol}$ of difference with $\mathrm{TS}(\mathrm{IIb})$ ), due to its connection with a secondary carbenium ion (with high free energy). This means that caution must be taken when equilibrating all type A isomerization steps, when secondary carbenium ions are concerned. 
In kinetic modeling, the intrinsic rotational entropy of the transition state for type B isomerization reactions is expected to be close to that of the carbenium ions. ${ }^{39}$ Considering the values reported in table $\mathrm{S} 8$ to $\mathrm{S} 10$ for gas phase simulations $(\mathrm{T} \Delta \mathrm{S}$ rot close to zero, which is a consequence of small changes in structures and in moments of inertia), these assumptions seem to be reasonable. The vibrational entropy of the transition state for type B isomerization reactions is also supposed to be roughly equal to that of the carbenium ions. ${ }^{39}$ This is found ( $\mathrm{T} \Delta \mathrm{S}_{\mathrm{vib}}$ in tables S8-S10 for gas phase simulations) to be more debatable: as also found in our previous work, the type $\mathrm{B}$ isomerization transition states are more constrained than the corresponding reactant and products, mainly due to entropic vibrational contributions (of the order of 10 to $15 \mathrm{~kJ} / \mathrm{mol}$ at $500 \mathrm{~K}$ ). Thus, in the end, considering that the carbenium species have lost all translational degrees of freedom, the activation entropy is set to zero (same entropy for the carbenium and edge-protonated PCPs) in the kinetic models. ${ }^{39}$ We claim that this leads to an overestimation of the pre-factor, likely compensated by an overestimation of the activation energy in the course of the fitting.

Concerning the enthalpy components, the composite isomerization activation energies are defined in some single-event models as the sum of the intrinsic isomerization activation energy (from the carbenium playing the role of the reactant) and the protonation enthalpy of the corresponding physisorbed olefin. ${ }^{39}$ They are determined by fitting the experimental kinetic data. The composite rate constants for type $\mathrm{B}$ isomerization reactions connecting a secondary to a tertiary carbenium ion $(\mathrm{s}, \mathrm{t})$, and that of the reverse reaction $(\mathrm{t}, \mathrm{s})$, are supposed to be equal. ${ }^{39,42}$ Assuming that the energy levels of all physisorbed olefins are almost the same, this assumption is true, as by definition the transition state TS(I) connects secondary and tertiary carbenium ions in both directions (forward and backward). However, it would be incorrect to conclude that the intrinsic barriers are the same, if one considers the carbenium ions as the reactants. The $\mathrm{I}_{1}$ secondary carbenium is indeed far less stable (by 45 to $65 \mathrm{~kJ} / \mathrm{mol}$ 34 
at $500 \mathrm{~K}$ from tables $\mathrm{S} 6$ and $\mathrm{S} 7)$ than all tertiary carbenium ions modeled $\left(\mathrm{I}_{2}\right.$ and $\left.\mathrm{I}_{3}\right)$. This implies that the kinetic constant of the $(s, t)$ reaction is higher than that for the $(t, s)$ reaction. However, the secondary carbenium ion is not a stable intermediate, and is very easily converted into the corresponding $\pi$-complex (Figure 8 ), with a very moderate free energy barrier (close to $10 \mathrm{~kJ} / \mathrm{mol}$ at $500 \mathrm{~K}$, see Figure 6) and a non-negligible reaction free energy gain (close to $40 \mathrm{~kJ} / \mathrm{mol}$ at $500 \mathrm{~K}$ ). Thus, the kinetically relevant species is actually not the secondary carbenium ion, but the corresponding $\pi$-complex. If one considers the later as the reactant or product instead of the secondary carbenium, it indeed appears that the free energy barrier is similar for the $(\mathrm{s}, \mathrm{t})$ and the $(\mathrm{t}, \mathrm{s})$ processes, even if the higher the temperature, the more stable the tertiary carbenium will be with respect to the $\pi$-complex, making the $(\mathrm{t}, \mathrm{s})$ reaction somewhat slower as compared to the $(\mathrm{s}, \mathrm{t})$ one. Thus, our work provides a strong message for mechanistic interpretation of kinetic data: in the case of reactions involving secondary carbenium ions (poorly stable species), the kinetically relevant species is not the carbenium itself, but the corresponding $\pi$-complex, exhibiting comparable stability with tertiary carbenium ions.

The extraction of intrinsic isomerization enthalpies was proposed in some kinetic works, ${ }^{39,9}$ by subtracting to the composite enthalpies a protonation enthalpy determined by ab initio calculations (static, in gas phase). These values can be in principle compared to ours. They are, however, much too high (between 128 and $191 \mathrm{~kJ} / \mathrm{mol}$ from a tertiary carbenium, and between 98 and $147 \mathrm{~kJ} / \mathrm{mol}$ from a secondary carbenium) compared to our gas phase data $\left(\Delta \mathrm{U}_{\text {total }}\right.$ of activation: 12 and $75 \mathrm{~kJ} / \mathrm{mol}$ at $500 \mathrm{~K}$ from a secondary and tertiary ion respectively) and the uncertainty is very large, with a strong dependence on the model used for the estimation of the protonation enthalpies (with differences from 30 to $70 \mathrm{~kJ} / \mathrm{mol}$ ). Note that our $(\mathrm{t}, \mathrm{t})$ activation enthalpy of $75 \mathrm{~kJ} / \mathrm{mol}$ is in excellent agreement with the extrapolation at $453 \mathrm{~K}^{41}$ of the data obtained in super-acidic media at lower temperature. ${ }^{11}$ The deviation 35 
between our results and the kinetic modeling estimates can tentatively be assigned to the difficult estimation of the protonation enthalpy, and the issue with the overestimated prefactor (entropy component), likely leading to an overestimation of the activation energies in kinetic fitting by compensation. Thus, in the end, the zeolite catalyst seems to behave more closely to a super-acid than previously thought. ${ }^{39}$

Finally, single event modeling also made the comparison between $(t, t)$ and $(s, t)=(t, s)$ type $\mathrm{B}$ isomerization rates possible. In our simulations, no clear trend emerges, the free energy levels of $\mathrm{TS}(\mathrm{I})$ and $\mathrm{TS}(\mathrm{IIb})$ being comparable, in agreement with the weak difference indicated in kinetic modeling. ${ }^{39,34}$

In the end, mechanisms I and II are coupled as they represent two alternatives to reach the same products. Despite the very low stability of the secondary carbenium, we find that the corresponding $\pi$-complex is a relevant connected stable intermediate. The global free energy barriers of both mechanisms appear to be very close, and in a slight favor of mechanism I (through direct isomerization of the secondary carbenium) when the temperature is increased from $300 \mathrm{~K}$ to $500 \mathrm{~K}$. Thus, it remains important to include such options in the kinetic modeling, as done in the previous single-event investigations, although at that time the secondary carbenium were believed to be stable intermediates.

\section{CONCLUSION}

In this work, a detailed ab initio molecular dynamics study of isomerization transformation of 4-methyl-hex-1-ene into 2,4-dimethyl-penten-2-ium cation has been presented. In addition to the conventional one-step mechanism (mechanism I), consisting in a proton transfer from the zeolite followed by a type B isomerization transforming a secondary carbenium into a tertiary carbenium, an alternative reaction route, (mechanism II) has been described. This mechanism 
consists of two steps involving (i) proton transfer from the zeolite and an intramolecular 1,3 hydride-shift producing a tertiary carbenium, and (ii) a type B isomerization between two tertiary carbenium ions. The global kinetic picture that we get from these simulations is summarized in Scheme 1, together with data obtained in our previous work. ${ }^{31}$

a)

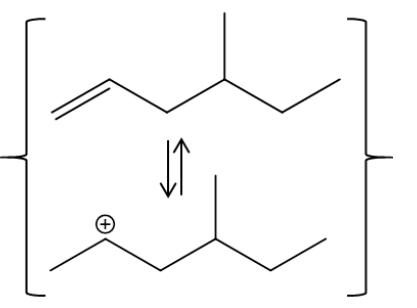

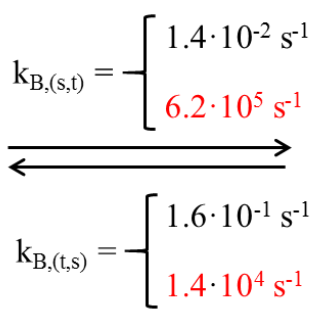
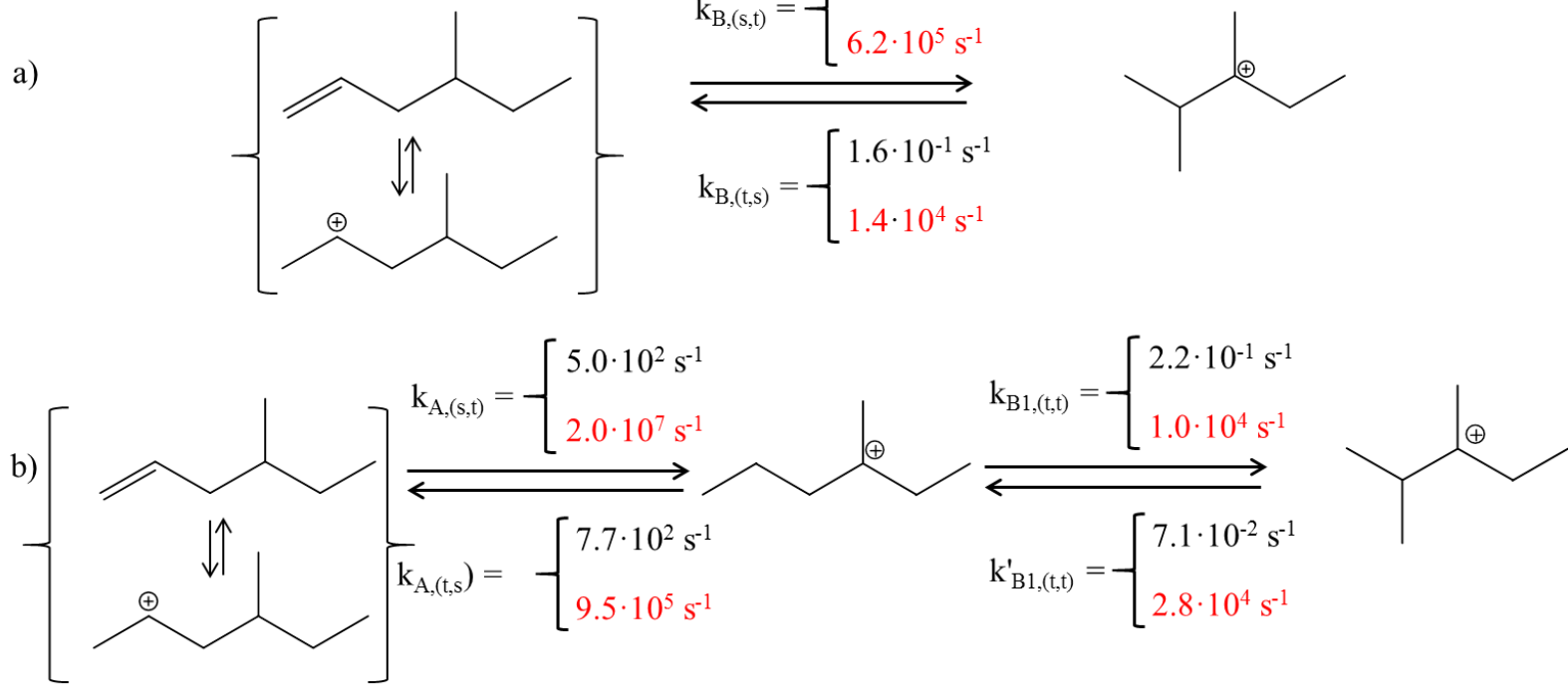

c)
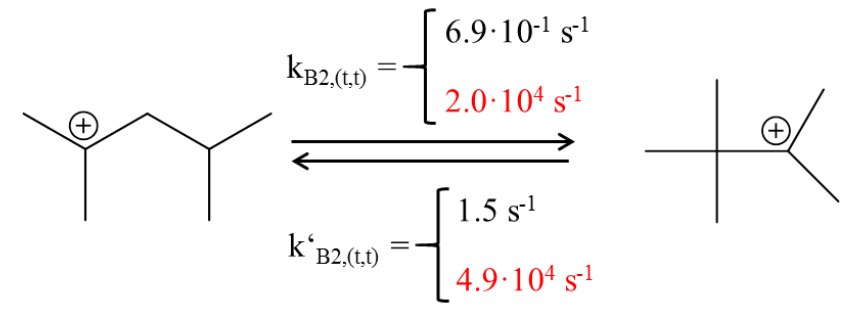

$$
\underset{\mathrm{k}_{\mathrm{A},(\mathrm{t}, \mathrm{t})}^{\prime}=\mathrm{k}_{\mathrm{A},(\mathrm{t}, \mathrm{t})}}{\stackrel{\left[\begin{array}{l}
1.6 \\
1.6 \cdot 10^{10} \mathrm{~s}^{-1}
\end{array}\right.}{2.8 \cdot 10^{11} \mathrm{~s}^{-1}}}
$$

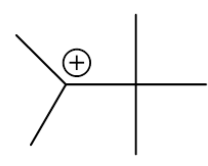

Scheme 1. Kinetic constants estimated by ab initio molecular dynamics at $300 \mathrm{~K}$ (black) and $500 \mathrm{~K}$ (red) for type A and B isomerization reactions starting from 4-methyl-hex-1-ene (a) mechanism I and b) mechanism II) and from 2,4-dimethyl-penten-2-ium cation (c). ${ }^{31} \mathrm{k}_{\mathrm{B}}$ and $\mathrm{k}_{\mathrm{A}}$ stand for rate constants determined for type B and A isomerization reaction, respectively, and the nature of the carbenium ion is symbolized by s (secondary) or t (tertiary). When available, and when more stable than the corresponding carbenium ion, the $\pi$-complex was used as the reference state for the calculation of the rate constant instead of the carbenium ion. 
The main conclusions that we obtain are the following:

- The secondary carbenium ion is a poorly stable species, even not defined as a free energy minimum in some conditions. In this case, the kinetically relevant species is the corresponding $\pi$-complex (linked to the secondary carbenium ion by a protonation-deprotonation reaction).

- All transition states calculated for type B isomerization reactions exhibit comparable stability and structure (edge-protonated cyclopropane), suggesting a certain level of universality of the present findings.

- Consistently with empirical knowledge, transition states for type A isomerization reactions are more stable than those of type $\mathrm{B}$ isomerization reactions. The transition state structure can, however, differ from one type of reaction to another. Whereas for methyl shifts a corner-PCP plays the role of the transition state, in the case of the 1,3 hydride shift, an edge-PCP is found, which is more stable than the one found for type B isomerization reactions. One of the $\mathrm{C}-\mathrm{C}$ bonds of the triangle is longer than for type B edge-PCPs.

- Increasing the temperature from 300 to $500 \mathrm{~K}$ leads to a systematic stabilization of carbenium ions with respect to the neutral $\pi$-complex. Such stabilization is generally stronger for intermediates than for PCPs.

In the end, both mechanisms (I and II) significantly contribute to the global reaction rate, with a predominance of mechanism I (type B isomerization connecting a tertiary and a secondary carbenium ion) at $500 \mathrm{~K}$. A priori, mechanism II should have been preferred over mechanism I, as it is expected to quickly convert a secondary carbenium into a tertiary carbenium by a type A isomerization. We however see that this is an oversimplified picture, that eventually depends on thermal effects. Also, it appears from Scheme 1 that for the cases 
investigated at $500 \mathrm{~K}$, the monobranched to dibranched transformation is quicker than the dibranched to tribranched transformation.

This work brings new quantified data and mechanistic information that may help the building of more relevant kinetic models in the future. The species investigated herein being also susceptible of cracking at high conversion, ${ }^{35}$ additional data are also required for these reactions as well. 


\section{AUTHOR INFORMATION}

\section{Corresponding Authors}

*celine.chizallet@ifpen.fr; tomas.bucko@uniba.sk

\section{SUPPORTING INFORMATION}

The following information are given in the Supporting information file: Supercell of chabazite; Rotational isomers of the species involved in both mechanisms; Determination of the velocity term ; Probability distribution functions for reactant, intermediate and product states of isomerization reactions; Ways to avoid by-reactions; Kinetic analysis; Static calculations for the gas phase reactions; Structural data; Interaction of alkene in the reactant state with the acid site of the zeolite; Statistical Error Estimations; Variation of selected geometric parameters along the reaction coordinate for the different mechanisms.

\section{ACKNOWLEDGMENT}

This work was performed using HPC resources from GENCI-IDRIS (Grant A0060806134, the IFPEN ENER220 supercomputer, and the supercomputing infrastructure of Computing Center of the Slovak Academy of Sciences acquired in projects ITMS 26230120002 and 26210120002 supported by the Research and Development Operational Program funded by the ERDF. J.R. thanks Pablo G. Rey for help in writing post-processing scripts. TB acknowledges support from the Slovak Research and Development Agency under the Contracts No. APVV-15-0105 and No. VEGA-1/0777/19, and the financial support from IFP Energies nouvelles. 


\section{References}

(1) Zečević, J.; Vanbutsele, G.; Jong, K. P. de; Martens, J. A. Nanoscale Intimacy in Bifunctional Catalysts for Selective Conversion of Hydrocarbons. Nature 2015, 528, 245248.

(2) Marcilly, C. Acido-Basic Catalysis. Application to Refining and Petrochemistry; Technip, 2005 .

(3) Gutierrez-Acebo, E.; Leroux, C.; Chizallet, C.; Schuurman, Y.; Bouchy, C. Metal/Acid Bifunctional Catalysis and Intimacy Criterion for Ethylcyclohexane Hydroconversion. ACS Catal. 2018, 8, 6035-6046.

(4) Martens, J. A.; Verboekend, D.; Thomas, K.; Vanbutsele, G.; Gilson, J.-P.; PérezRamírez, J. Hydroisomerization of Emerging Renewable Hydrocarbons Using Hierarchical Pt/H-ZSM-22 Catalyst. ChemSusChem 2013, 6, 421-425.

(5) Jacobs, P. A.; Dusselier, M.; Sels, B. F. Will Zeolite-Based Catalysis Be as Relevant in Future Biorefineries as in Crude Oil Refineries? Angew. Chem. Int. Ed. 2014, 53, 8621-8626.

(6) Phan, D.-P.; Lee, E. Catalytic Hydroisomerization Upgrading of Vegetable Oil-Based Insulating Oil. Catalysts 2018, 8, 131.

(7) Bouchy, C.; Hastoy, G.; Guillon, E.; Martens, J. A. Fischer-Tropsch Waxes Upgrading via Hydrocracking and Selective Hydroisomerization. Oil Gas Sci. Technol. - Rev. IFP Energies nouvelles 2009, 64, 91-112.

(8) Weitkamp, J. Catalytic Hydrocracking-Mechanisms and Versatility of the Process. ChemCatChem 2012, 4, 292-306.

(9) Thybaut, J. W.; Narasimhan, L. C. S.; Marin, G. B.; Denayer, J. F.M.; Baron, G. V.; Jacobs, P. A.; Martens, J. A. Alkylcarbenium Ion Concentrations in Zeolite Pores During Octane Hydrocracking on Pt/H-USY Zeolite. Catal. Lett. 2004, 94, 81-88. 
(10) Olah, G. A. General Concept and Structure of Carbocations Based on Differentiation of Trivalent (Classical) Carbenium Ions from Three-Center Bound Penta- or Tetracoordinated (Nonclassical) Carbonium Ions. The Role of Carbocations in Electrophilic Reactions. J. Am. Chem. Soc. 1972, 94, 808-820.

(11) Brouwer, D. M.; Hogeven H. Electrophilic Substitutions at Alkanes and in Alkylcarbonium Ions. Prog. Phys. Org. Chem. 1972, 9, 179-240.

(12) Nicholas, J. B.; Haw, J. F. The Prediction of Persistent Carbenium Ions in Zeolites. J. Am. Chem. Soc. 1998, 120, 11804-11805.

(13) Ivanova, I. I.; Kolyagin, Y. G. Impact of in Situ MAS NMR Techniques to the Understanding of the Mechanisms of Zeolite Catalyzed Reactions. Chem. Soc. Rev. 2010, 39, $5018-5050$.

(14) Dai, W.; Wang, C.; Yi, X.; Zheng, A.; Li, L.; Wu, G.; Guan, N.; Xie, Z.; Dyballa, M.; Hunger, M. Identification of tert-Butyl Cations in Zeolite H-ZSM-5: Evidence from NMR Spectroscopy and DFT Calculations. Angew. Chem. Int. Edit. 2015, 54, 8783-8786.

(15) Huang, M.; Wang, Q.; Yi, X.; Chu, Y.; Dai, W.; Li, L.; Zheng, A.; Deng, F. Insight into the Formation of the tert-butyl Cation Confined inside H-ZSM-5 Zeolite from NMR Spectroscopy and DFT Calculations. Chem. Commun. 2016, 52, 10606-10608.

(16) Kazansky, V. B.; Senchenya, I. N. Quantum Chemical Study of the Electronic Structure and Geometry of Surface Alkoxy Groups as Probable Active Intermediates of Heterogeneous Acidic Catalysts. What Are The Adsorbed Carbenium Ions? J. Catal. 1989, 119, 108-120. (17) Frash, M. V.; Kazansky, V. B.; Rigby, R. A.; van Santen, R. A. Cracking of Hydrocarbons on Zeolite Catalysts: Density Functional and Hartree-Fock Calculations on the Mechanism of the $\beta$-Scission Reaction. J. Phys. Chem. B 1998, 102, 2232-2238.

(18) Denayer, J. F.; Baron, G. V.; Vanbutsele, G.; Jacobs, P. A.; Martens, J. A. Evidence for Alkylcarbenium Ion Reaction Intermediates from Intrinsic Reaction Kinetics of C6-C9 n- 
Alkane Hydroisomerization and Hydrocracking on Pt/H-Y and Pt/USY Zeolites. J. Catal. 2000, $190,469-473$.

(19) Boronat, M.; Viruela, P. M.; Corma, A. Reaction Intermediates in Acid Catalysis by Zeolites: Prediction of the Relative Tendency to form Alkoxides or Carbocations as a Function of Hydrocarbon Nature and Active Site Structure. J. Am. Chem. Soc. 2004, 126, $3300-3309$.

(20) Leydier, F.; Chizallet, C.; Costa, D.; Raybaud, P. Revisiting Carbenium Chemistry on Amorphous Silica-Alumina: Unraveling their Milder Acidity as Compared to Zeolites. J. Catal. 2015, 325, 35-47.

(21) Rey, J.; Raybaud, P.; Chizallet, C. Ab Initio Simulation of the Acid Sites at the External Surface of Zeolite Beta. ChemCatChem 2017, 9, 2176-2185.

(22) Ester Gutierrez-Acebo; Rey, J.; Bouchy, C.; Schuurman, Y.; Chizallet, C. Location of the Active Sites for Ethylcyclohexane Hydroisomerization by Ring Contraction and Expansion in the EUO Zeolitic Framework. ACS Catal. 2019, 9, 1692-1704.

(23) Tuma, C.; Sauer, J. Protonated Isobutene in Zeolites: tert-butyl Cation or Alkoxide? Angew. Chem. Int. Edit. 2005, 44, 4769-4771.

(24) Tuma, C.; Sauer, J. Treating Dispersion Effects in Extended Systems by Hybrid MP2:DFT Calculations-Protonation of Isobutene in Zeolite Ferrierite. Phys. Chem. Chem. Phys. 2006, 8, 3955-3965.

(25) Tuma, C.; Kerber, T.; Sauer, J. The tert-butyl Cation in H-Zeolites: Deprotonation to Isobutene and Conversion into Surface Alkoxides. Angew. Chem. Int. Edit. 2010, 49, 46784680.

(26) Cnudde, P.; Wispelaere, K. de; van der Mynsbrugge, J.; Waroquier, M.; van Speybroeck, V. Effect of Temperature and Branching on the Nature and Stability of Alkene Cracking Intermediates in H-ZSM-5. J. Catal. 2017, 345, 53-69. 
(27) Hajek, J.; van der Mynsbrugge, J.; Wispelaere, K. de; Cnudde, P.; Vanduyfhuys, L.; Waroquier, M.; van Speybroeck, V. On the Stability and Nature of Adsorbed Pentene in Brønsted Acid Zeolite H-ZSM-5 at 323K. J. Catal. 2016, 340, 227-235.

(28) Cnudde, P.; Wispelaere, K. de; Vanduyfhuys, L.; Demuynck, R.; van der Mynsbrugge, J.; Waroquier, M.; van Speybroeck, V. How Chain Length and Branching Influence the Alkene Cracking Reactivity on H-ZSM-5. ACS Catal. 2018, 8, 9579-9595.

(29) van Speybroeck, V.; Hemelsoet, K.; Joos, L.; Waroquier, M.; Bell, R. G.; Catlow, C. R. A. Advances in Theory and their Application within the Field of Zeolite Chemistry. Chem. Soc. Rev. 2015, 44, 7044-7111.

(30) Bučko, T.; Benco, L.; Hafner, J.; Ángyán, J. G. Monomolecular Cracking of Propane over Acidic Chabazite. J. Catal. 2011, 279, 220-228.

(31) Rey, J.; Gomez, A.; Raybaud, P.; Chizallet, C.; Bučko, T. On the Origin of the Difference Between Type A and Type B Skeletal Isomerization of Alkenes Catalyzed by Zeolites: The Crucial Input of ab initio Molecular Dynamics. J. Catal. 2019, 373, 361-373. (32) Carter, E. A.; Ciccotti, G.; Hynes, J. T.; Kapral, R. Constrained Reaction Coordinate Dynamics for the Simulation of Rare Events. Chem. Phys. Lett. 1989, 156, 472-477.

(33) Ciccotti, G.; Sprik, M. Free Energy from Constrained Molecular Dynamics. J. Chem. Phys. 1998, 109, 7737-7744.

(34) Thybaut, J.W.; Marin, G.B.; Baron, G.V.; Jacobs, P.A.; Martens, J.A. Alkene Protonation Enthalpy Determination from Fundamental Kinetic Modeling of Alkane Hydroconversion on Pt/H-(US)Y-Zeolite. J. Catal. 2001, 202, 324-339.

(35) Raybaud, P.; Patrigeon, A.; Toulhoat, H. The Origin of the C7-Hydroconversion Selectivities on Y, $\beta$, ZSM-22, ZSM-23, and EU-1 Zeolites. J. Catal. 2001, 197, 98-112. 
(36) Demuth, T.; Rozanska, X.; Benco, L.: Hafner, J.; van Santen, R. A.; Toulhoat, H.

Catalytic Isomerization of 2-pentene in H-ZSM-22-A DFT Investigation. J. Catal. 2003, $214,68-77$.

(37) Huang, B.; Bai, P.; Neurock, M.; Davis, R. J. Conversion of n-Hexane and n-Dodecane over H-ZSM-5, H-Y and Al-MCM-41 at Supercritical Conditions. Appl. Catal. A-Gen. 2017, $546,149-158$.

(38) Natal-Santiago, M. A.; Alcalá, R.; Dumesic, J. A. DFT Study of the Isomerization of Hexyl Species Involved in the Acid-Catalyzed Conversion of 2-Methyl-Pentene-2. J. Catal. 1999, $181,124-144$.

(39) Martens, G. G.; Marin, G. B.; Martens, J. A.; Jacobs, P. A.; Baron, G. V. A Fundamental Kinetic Model for Hydrocracking of C8 to C12 Alkanes on Pt/US-Y Zeolites. J. Catal. 2000, $195,253-267$.

(40) Brouwer, D. M.; van Doorn, J. A. Spectroscopic Observation of a 1,3-Hydrogen Shift in 2,4-Dimethylpentyl Cation. Recl. Trav. Chim. Pays-Bas 1969, 88, 573-576.

(41) Baltanas, M. A.; van Raemdonck, K. K.; Froment, G. F.; Mohedas, S. R. Fundamental Kinetic Modeling of Hydroisomerization and Hydrocracking on Noble Metal-Loaded Faujasites. 1. Rate Parameters for Hydroisomerization. Ind. Eng. Chem. Res. 1989, 28, 899910.

(42) Schweitzer, J.-M.; Galtier, P.; Schweich, D. A Single Events Kinetic Model for the hydrocracking of Paraffins in a Three-Phase Reactor. Chem. Eng. Sci. 1999, 54, 2441-2452. (43) Kresse, G.; Hafner, J. Ab Initio Molecular Dynamics for Liquid Metals. Phys. Rev. B $1993,47,558-561$.

(44) Kresse, G.; Hafner, J. Ab Initio Molecular-Dynamics Simulation of the Liquid-MetalAmorphous-Semiconductor Transition in Germanium. Phys. Rev. B 1994, 49, 14251-14269. 
(45) Kresse, G.; Furthmüller, J. Efficient iterative schemes for ab initio total-energy calculations using a plane-wave basis set. Phys. Rev. B 1996, 54, 11169-11186.

(46) Blöchl, P. E. Projector Augmented-Wave Method. Phys. Rev. B 1994, 50, 17953-17979.

(47) Kresse, G.; Joubert, D. From Ultrasoft Pseudopotentials to the Projector AugmentedWave Method. Phys. Rev. B 1999, 59, 1758-1775.

(48) Perdew, J. P.; Burke, K.; Ernzerhof, M. Generalized Gradient Approximation Made Simple. Phys. Rev. Lett. 1996, 77, 3865-3868.

(49) Grimme, S. Semiempirical GGA-Type Density Functional Constructed with a LongRange Dispersion Correction. J. Comput. Chem. 2006, 27, 1787-1799.

(50) Göltl, F.; Grüneis, A.; Bučko, T.; Hafner, J. Van der Waals Interactions between Hydrocarbon Molecules and Zeolites: Periodic Calculations at Different Levels of Theory, from Density Functional Theory to the Random Phase Approximation and Møller-Plesset Perturbation Theory. J. Chem. Phys. 2012, 137, 114111.

(51) Silaghi, M.-C.; Chizallet, C.; Petracovschi, E.; Kerber, T.; Sauer, J.; Raybaud, P. Regioselectivity of Al-O Bond Hydrolysis during Zeolites Dealumination Unified by Brønsted-Evans-Polanyi Relationship. ACS Catal. 2015, 5, 11-15.

(52) Bučko, T.; Hafner, J.; Lebègue, S.; Ángyán, J. G. Improved Description of the Structure of Molecular and Layered Crystals. J. Phys. Chem. A 2010, 114, 11814-11824.

(53) Bučko, T.; Hafner, J.; Angyán, J. G. Geometry Optimization of Periodic Systems Using Internal Coordinates. J. Chem. Phys. 2005, 122, 124508.

(54) Bučko, T. Transition state optimization of periodic systems using delocalized internal coordinates. Theor. Chem. Acc. 2018, 137, 164.

(55) Fukui, K. Formulation of the Reaction Coordinate. J. Phys. Chem. 1970, 74, 4161-4163.

(56) Fukui, K. The Path of Chemical Reactions - the IRC Approach. Accounts Chem. Res. 1981, 14, 363-368. 
(57) Hratchian, H. P.; Schlegel, H. B. Following Reaction Pathways Using a Damped Classical Trajectory Algorithm. J. Phys. Chem. A 2002, 106, 165-169.

(58) Frenkel, D.; Smit, B. Understanding Molecular Simulation. From Algorithms to Applications; Computational science series; Academic Press, 2002.

(59) Bučko, T.; Chibani, S.; Paul, J.-F.; Cantrel, L.; Badawi, M. Dissociative Iodomethane Adsorption on Ag-MOR and the Formation of AgI clusters: An Ab Initio Molecular Dynamics Study. Phys. Chem. Chem. Phys. 2017, 19, 27530-27543.

(60) Bučko, T. Ab Initio Calculations of Free-Energy Reaction Barriers. J. Phys. Condens. Matter. 2008, 20, 64211.

(61) Bučko, T.; Hafner, J. The Role of Spatial Constraints and Entropy in the Adsorption and Transformation of Hydrocarbons catalyzed by zeolites. J. Catal. 2015, 329, 32-48.

(62) Laio, A.; Parrinello, M. Escaping Free-Energy Minima. Proc. Natl. Acad. Sci. U.S.A. 2002, 99, 12562-12566.

(63) Rasul, G.; Prakash, G. K. S.; Olah, G. A. MP2, CCSD(T), and Density Functional Theory Study of the 2-Butyl Cation: New Insight into the Methyl- and Hydrogen-Bridged Structures. J.Phys.Chem. A 2015, 119, 5762-5769.

(64) Vrček, I. V.; Vrček, V.; Siehl, H.-U. Quantum Chemical Study of Degenerate Hydride Shifts in Acyclic Tertiary Carbocations. J. Phys. Chem. A 2002, 106, 1604-1611.

(65) Olah, G. A.; Prakash, G. K. S.; Rasul, G. Ab Initio/GIAO-CCSD(T) ${ }^{13}$ C NMR Study of the Rearrangement and Dynamic Aspects of Rapidly Equilibrating Tertiary Carbocations, $\mathrm{C}_{6} \mathrm{H}_{13}{ }^{+}$and $\mathrm{C}_{7} \mathrm{H}_{15}{ }^{+} . J$. Comput. Chem 2016, 37, 70-77.

(66) Collins, C. J. Protonated Cyclopropanes. Chem. Rev. 1969, 69, 543-550.

(67) Karabatsos, G. J.; Orzech, C. E. Carbonium Ion Rearrangements. V.11,3-Hydride Shifts in the 1-Propyl Cation. J. Am. Chem. Soc. 1962, 84, 2838-2839. 
(68) Lee, C. C.; Gruber, L. Protonated Cyclopropanes. II. The Solvolysis of Cyclopropane in Tritiated Sulfuric Acid. J. Am. Chem. Soc. 1968, 90, 3775-3778.

(69) Piccini, G.; Alessio, M.; Sauer, J. Ab Initio Calculation of Rate Constants for MoleculeSurface Reactions with Chemical Accuracy. Angew. Chem. Int. Edit. 2016, 55, 5235-5237. (70) Rybicki, M.; Sauer, J. Ab Initio Prediction of Proton Exchange Barriers for Alkanes at Brønsted Sites of Zeolite H-MFI. J. Am. Chem. Soc. 2018, 140, 18151-18161.

(71) Plessow, P. N.; Studt, F. Olefin Methylation and Cracking Reactions in H-SSZ-13 Investigated with ab initio and DFT Calculations. Catal. Sci. Technol. 2018, 8, 4420-4429.

(72) Goncalves, T. J.; Plessow, P. N.; Studt, F. On the Accuracy of Density Functional Theory in Zeolite Catalysis. ChemCatChem 2019, in press, 10.1002/cctc.201900791. (73) Rocca, D.; Dixit, A.; Badawi, M.; Lebègue, S.; Gould, T.; Bučko, T. Bridging Molecular Dynamics and Correlated Wave-Function Methods for Accurate Finite-Temperature Properties. Phys. Rev. Materials 2019, 3, 040801(R).

(74) Wynne-Jones, W. F. K.; Eyring, H. The Absolute Rate of Reactions in Condensed Phases. J. Chem. Phys. 1935, 3, 492-502.

(75) Oliveira, L. P. de; Hudebine, D.; Guillaume, D.; Verstraete, J. J.; Joly, J. F. A Review of Kinetic Modeling Methodologies for Complex Processes. Oil Gas Sci. Technol. - Rev. IFP Energies nouvelles 2016, 71, 45.

(76) Mendes, P. S. F.; Silva, J. M.; Ribeiro, M. F.; Duchêne, P.; Daudin, A.; Bouchy, C. Quantification of metal-acid balance in hydroisomerization catalysts: A step further toward catalyst design. AIChE J. 2017, 63, 2864-2875.

(77) Surla, K.; Guillaume, D.; Verstraete, J. J.; Galtier, P. Kinetic Modeling using the SingleEvent Methodology. Oil Gas Sci. Technol. - Rev. IFP Energies nouvelles 2011, 66, 343-365. 
(78) Vandegehuchte, B. D.; Thybaut, J. W.; Marin, G. B. Unraveling Diffusion and Other Shape Selectivity Effects in ZSM5 Using n -Hexane Hydroconversion Single-Event Microkinetics. Ind. Eng. Chem. Res. 2014, 53, 15333-15347.

(79) Valéry, E.; Guillaume, D.; Surla, K.; Galtier, P.; Verstraete, J.; Schweich, D. Kinetic Modeling of Acid Catalyzed Hydrocracking of Heavy Molecules. Ind. Eng. Chem. Res. 2007, $46,4755-4763$. 
Graphical TOC

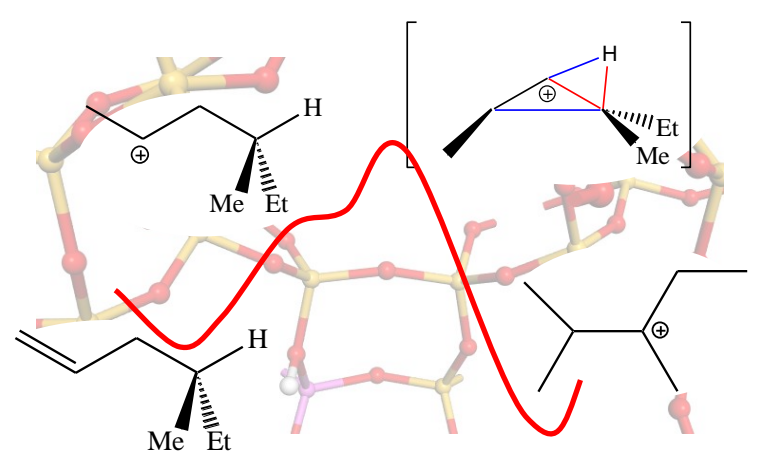

